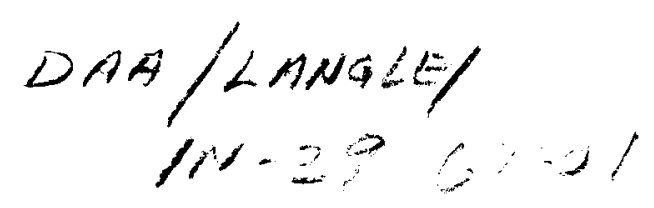

DEPARTMENT OF MECHANICAL ENGINEERING AND MECHANICS COLLEGE OF ENGINEERING AND TECHNOLOGY

OLD DOMINION UNIVERSITY

NORFOLK, VIRGINIA 23508

MULTIPLE-MODE NONLINEAR FREE AND FORCED VIBRATIONS OF BEAMS USING FINITE ELEMENT METHOD

By

Chuh Mei, Principal Investigator

and

Kamolphan Decha-IJmphai, Graduate Research, Assistant,

Final Report

For the period ended January 31, 1987

Prepared for the

National Aeronautics and Space Administration

Langley Research Center

Hamptor, Virginia 23665

Under

Research Grant NAG-1-301

Joseph E. Walz, Technical Monitor

SDD-Structural Dynamics Branch

(NASA-CR-1805ミE) UULTIELE-ECLE NCALINEAB

FEEE AND FOBCED VIEBATICNS CE EFALS USIAG

N87-26367

FINITE ELEAENT EEIEOD Final EEFCrt, period

ending $31 \mathrm{Jan}$. 19k7 (Cld ECainicn Oniv-)

$91 \mathrm{p}$ Avail: ATIS EC AC5/HF AC1 CSCL $20 \mathrm{~K}$ G3/39 0069601 
DEPARTMENT OF MECHANICAL ENGINEERING AND MECHANICS COLLEGE OF ENGINEERING AND TECHNOLOGY

OLD DOMINION UNIVERSITY

NORFOLK, VIRGINIA 23508

MULTIPLE-MODE NONLINEAR FREE AND FORCED VIBRATIONS OF BEAMS USING FINITE ELEMENT METHOD

By

Chuh Mei, Principal Investigator

and

Kamolphan Decha-Umphai, Graduate Research Assistant

Final Report

For the period ended January 31, 1987

Prepared for the

National Aeronautics and Space Administration

Langley Research Center

Hampton, Virginia 23665

Under

Research 6rant MAG-1-301

Joseph E. Walz, Technical Monitor

SDD-Structura1 Dynamics Branch

Submitted by the

01d Dominion University Research Foundation

P.0. Box 6369

Norfolk, Virginia 23508 


\title{
MULTIPLE-MODE NONLINEAR FREE AND FORCED VIBRATIONS \\ OF BEAMS USING FINITE ELEMENT METHOD
}

\author{
Chuh $\mathrm{Mei}^{\star}$ and Kamolphan Decha-Umphai ${ }^{\star *}$ \\ old Dominion University, Norfolk, Virginia
}

\begin{abstract}
Multiple-mode nonlinear free and forced of beam has been analyzed by the finite element method. The geometric nonlinearity is investigated. Inplane (longitudinal) displacement and inertia (IDI) are also considered in the formulation. Harmonic force matrix is derived and explained. Nonlinear free vibration can be simply treated as a special case of the general forced vibration by setting the harmonic force matrix equal to zero. The effect of the higher modes is more pronounced for the clamped supported beam than the simply supported one. Beam without inplane displacement and inertia (IDI) yields more effect of the higher modes than the one with inplane displacement and inertia. The effects of inplane displacement and inertia are to reduce nonlinearity. [For beams with end supports restrained from axial movement (immovable case), only the hardening type nonlinearity is observed]. However, beams of small slenderness ratio $(L / R=20)$ with movable end supports, the softening type nonlinearity is found. The concentrated force case yields a more severe response than the uniformly distributed force case. Finite element results are in good agreements with the solutions of simple elliptic response, harmonic balance method, Runge-Kutta method and experiment.
\end{abstract}

\footnotetext{
Professor, Department of Mechanical Engineering and Mechanics ** Graduate Student
} 


\section{TABLE OF CONTENTS}

ABSTRACT

1. INTRODUCTION............................... 1

2. CLASSICAL FORMULATIONS ........................ 11

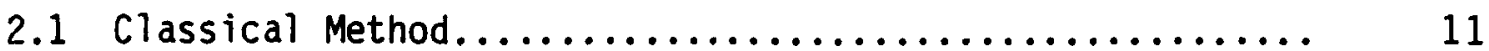

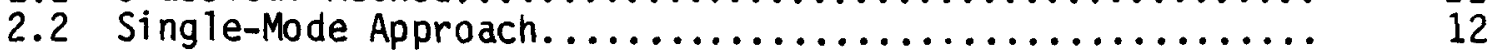

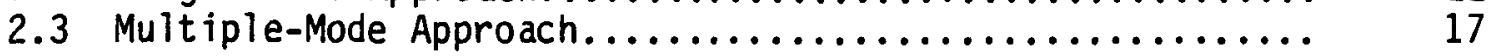

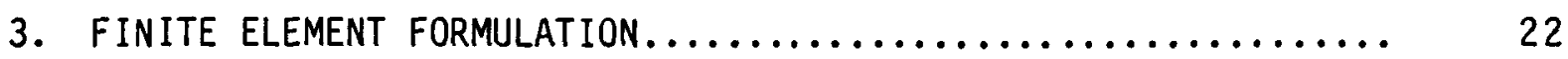

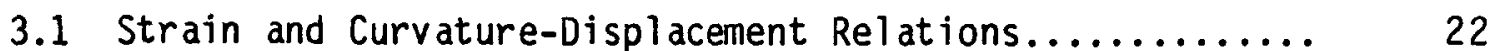

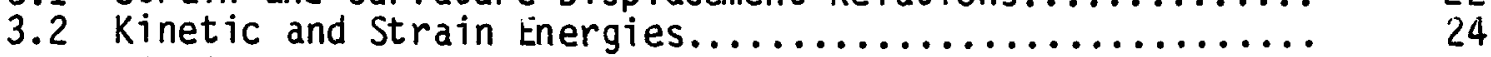

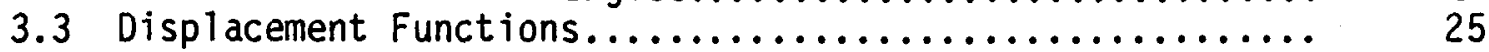

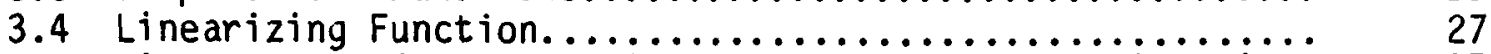

3.5 Element Equations of Motion for Noni inear Free Vibration. $\quad 27$

3.6 Element Harmonic Force Matrix.................... 30

3.7 Element Equations of Motion for Nonlinear Forced

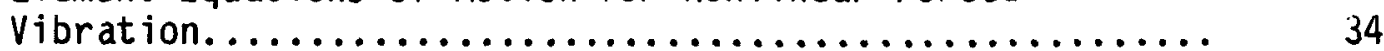

4. SOLUTIONS PROCEDURES........................... 35

4.1 Small Deflection Solution (Linear Solution)............ 35

4.2 Large Amplitude Solution (Nonlinear Solution) ........... 37

4.3 Convergence Criteria......................... 41

5. RESULTS AND DISCUSSIONS........................ 46

5.1 Boundary Conditions and Material Properties............ 46

5.2 Improved Nonlinear Free Vibration................... 47

5.3 Nonlinear Response to Distributed Harmonic Force.......... 61

5.4 Nonlinear Response to Concentrated Harmonic Force........ 68

6. CONCLUSIONS................................ 80

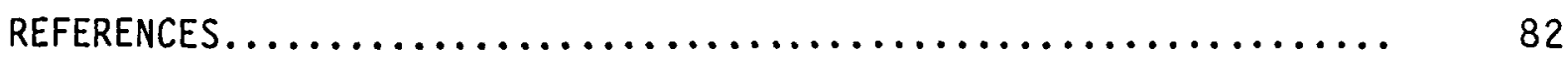

APPENDIX: CONVERGENCE CRITERIA.................... 85

\section{LIST OF TABLES}

Table

Page

1 Relations between slenderness ratio $(L / R)$ and beam length..

2 Frequency ratios for nonlinear free vibration of clamped and simply supported beams $(L / R=1010)$ without inplane

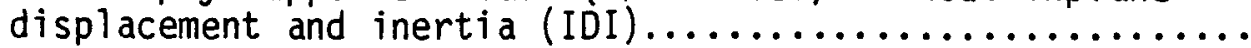




\section{TABLE OF CONTEMTS (Continued)}

\section{LIST OF TABLES (Continued)}

Table

Page

3 Amplitude ratios for nonlinear free vibration of $c$ lamped and simply supported beams $(L / R=1010)$ without inplane displacement and inertia (IDI) ......................

4 Comparison between Runge-Kutta method and finite element method for two-mode nonlinear free vibration of clamped and simply supported beams $(L / R=1010)$ without inplane

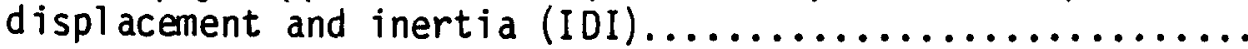

5 Frequency ratios for nonlinear free vibration of clamped and simply supported immovable beams $(L / R=1010)$ with inplane displacement and inertia (IDI) ...............

6 Amplitude ratios for nonlinear free vibration of $c l$ amped immovable beams $(L / R=1010)$ with inplane displacement

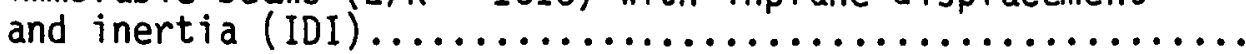

7 Frequency ratios $\left(\omega_{N 11} / \omega_{1}\right)$ for three-mode nonlinear free vibration of clamped and simply supported movable beams with inplane displacement and inertia (IDI) for different slenderness $r$ atio $(L / R) \ldots \ldots \ldots \ldots \ldots \ldots \ldots \ldots \ldots$

8 Amplitude.ratios for three-mode nonlinear free vibration of clamped and simply supported moveable beams $(L / R=20)$ with inplane displacement and inertia (IDI) ..............

9 Frequency ratios for nonlinear forced vibration of $c l$ amped and simply supported beams $(L / R=1010)$ without inplane displacement and inertia (IDI) under uniform harmonic

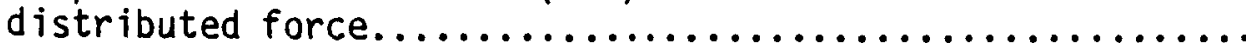

10 Amplitude ratios for nonlinear forced vibration of clamped and simply supported beams $(L / R=1010)$ without inplane displacement and inertia (IDI) under uniform

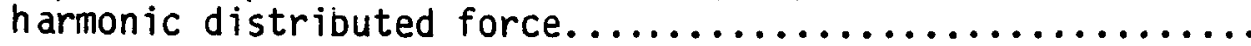

11 Frequency ratios for nonlinear forced vibration of clamped and simply supported immovable beams $(L / R=1010)$ with inplane displacement and inertia (IDI) under uniform

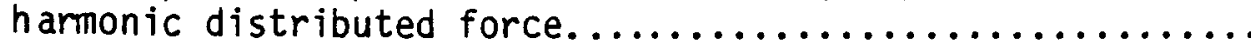

12 Amplitude ratios for nonlinear forced vibration of clamped immovable beam $(L / R=1010)$ with inplane displacement and inertia (IDI) under uniform harmonic distributed force; $F_{0}=0.002 \mathrm{~N} / \mathrm{mm} \ldots \ldots \ldots \ldots \ldots \ldots$ 
TABLE OF CONTENTS (Continued)

LIST OF TABLES (Concluded)

$\underline{T a b l e}$

Page

13 Frequency ratios and amplitude ratios for three-mode nonlinear forced vibration of $c l$ amped movable beam with inplane displacement and inertia (IDI) under uniform harmonic distributed force....................

14 Frequency ratios and amplitude ratios for three-mode nonlinear forced vibration of simply supported movable beam with inplane displacement and inertia (IDI) under uniform harmonic distributed force...................

15 Frequency ratios for three-mode forced vibration of clamped immovable beam $(L / R=1010)$ with inplane displacement and inertia (IDI) under concentrated harmonic force: total force $P=0.3 \mathrm{~N} . \ldots \ldots \ldots \ldots . . . . .$.

16 Frequency ratios for two-mode nonlinear forced vibration of simply supported immovable beam $(L / R=1010)$ with inplane displacement and inertia (IDI) under concentrated harmonic force: total force $P=0.15 \mathrm{~N}$.

\section{LIST OF FIGURES}

Figure

Page

1 Geometry of a clamped beam....................... 13

2 Beam element................................... 23

3 Computer flow-chart (solution procedures)............ 42

4 Convergence characteristics of a simply supported beam W/0 IDI, distributed force $F_{0}=0.001 \mathrm{~N} / \mathrm{mm}, 3$ modes

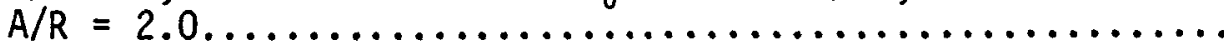

5 Convergence characteristics of a clamped beam W/IDI immovable. distributed force $F_{0}=0.002 \mathrm{~N} / \mathrm{imm}, 3$ modes,

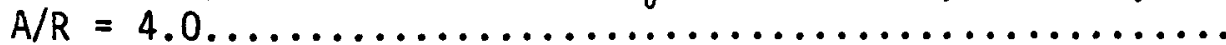

6 Clamped beam $W / 0$ IDI, 2 modes, $L / R=1010$, free vibration finite elenent method vs. Runge-Kutta method.............

7 Free vibration, simply supported beam W/0 IDI, 2 modes, $L / R=1010$, finite element method vs. Runge-Kutta method. .

8 Free vibration, immovable, W/IDI, 3 modes, clamped vs. simply supported beam.............................

9 Free vibration, clamped beam W/IDI, movable, 3 modes...... 
TABLE OF CONTENTS (Concluded)

LIST OF FIGURES (Concluded)

Figure

Page

10 Forced vibration, clamped beam, W/O IDI, immovable,

distributed force, 3 modes..........................

11 Forced vibration, simply supported beam, W/O IDI, distributed force, 3 modes..........................

12 Forced vibration, clamped beam, W/IDI, immovable, distributed force, 3 modes..........................

13 Forced vibration, clamped beam, immovable distributed force $F_{0}=0.004170277 \mathrm{~N} / \mathrm{mm}$ experiment vs. harmonic balance method vs. finite element method ( $W /$ IDI, 3 modes).

14 Forced vibration, clamped beam $W / I D I$, movable, $L / R=20$,

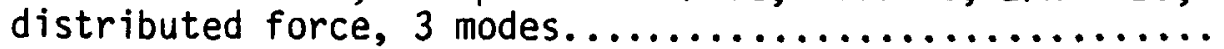

15 Forced vibration, $c l$ amped beam $W / I D I, L / R=100$, distributed force $F_{0}=20 \mathrm{~N} / \mathrm{mm}$, immovable vs. movable....

16 Forced vibration, clamped beam W/IDI, immovable, 3 modes, total force $0.3 \mathrm{~N}$, concentrated force vs. distributed

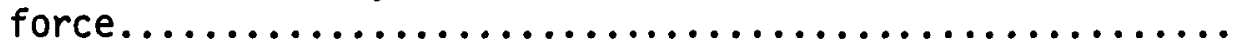

17 Forced vibration, simply supported beam W/IDI, immovable 2 modes, total force $0.15 \mathrm{~N}$, concentrated force vs. distributed force............................. 


\section{Chapter 1}

\section{INTRODUCTION}

In modern engineering, with its continuous refinement of instrumentation, its improved computational capabilities, and the high precision tolerances, the theory of nonlinear vibrations is gaining more and more practical meaning. Although it is known that linear vibrations provide no more than a first order approximation of an actual situation, they are sufficient for some practical and engineering purposes. The linear theory is inadequate, however, if the vibration of an elastic body involves amplitudes that are not very small, as assumed in the linear theory. Nonlinear vibration approach leads to completely new phenomena which are not possible in linear systems. For example, the dependence of frequency, or period of vibration, on amplitude cannot in principle be handled by using linear analyses. In such cases, nonlinear theory must be used to obtain more accurate results and to explain new phenomena. The steadily increasing demand for more realistic models of structural responses has resulted in solution techniques to deal with nonlinear structural problems. Apart from some few exceptions, it is generally not possible to provide analytical closed-form solutions for the differential equations occurring in nonlinear vibrations of structures. Naturally, a numerical solution may be obtained when the motion corresponding to certain initial and boundary conditions is to be determined. Because of the advance in electronics, modern digital computers have been of great value in solving nonlinear problems.

In general, nonlinearities in structural mechanics problems can arise in several ways. When material behavior is nonlinear, the 
generalized Hooke's law is no longer valid. This type of nonlinearity is called "material" or "physical" nonlinearity. Alternatively, material behavior can be assumed to be linear, but structural deformation can become large and cause nonlinear strain-displacement relations. Deformation of a structural member can also reach a magnitude that does not overstrain the material; in such a case, curvature of the deformed median line can no longer be expressed by a linear equation. Problems involving large structural deformation are called "geometrically" nonlinear problems. A combination of material nonlinearity and geometric nonlinearity is also possible.

Any large-amplitude deflection of a beam which is restrained axially at its two ends, results in some midplane stretching. This stretching must be accounted for by using nonlinear strain-displacement relationship (geometric nonlinearity). The nonlinear equation of motion describing this situation had been the basis of a number of investigations. Most of these works are based on a single-mode approach. Woinowsky-krieger ${ }^{1}$ considered the effect of an axial force on the vibration of hinged bars. The vibration of an extensible bar, carrying no transverse load and having the ends fixed at the supports, caused an axial tensile force with a period equal to the half-period of the transverse vibration of the bar. The elliptic function was used to produce the relation of frequency and amplitude of vibration. Eringen ${ }^{2}$ studied the nonlinear free vibrations of elastic bars having immovable hinged ends. The solution was accomplished by the use of the perturbation method. The ratio of nonlinear period over linear period and axial stress were shown against initial deflection. Only the hardening type nonlinearity was found. Burgreen ${ }^{3}$ studied the nonlinear 
free vibrations of a pin-ended column whose ends were pinned to points fixed in space. This imposed the condition of a constant end distance instead of the usual theoretical assumption that the axial load in the column remained constant along the beam length. The elliptic function was performed to get the exact solution. He also found that the frequency was dependent upon the amplitude of vibration, the effect of the amplitude of vibration becoming more pronounced as the Euler load was approached in which the classical linear theory yielded the frequency of vibration as zero. Wooda $17^{4}$ considered the nonlinear free vibrations of a thin elastic beam. In his formulation, a fixed inertial reference frame and a Lagrangian description of the motion were employed. By assuming the motion to be inextensional and, at the same time, admitting the existence of a resultant normal force acting on each cross-section of the beam, a system of governing equations was obtained. The solutions of the simply-supported beam were obtained by using three methods: the finite difference method, perturbation technique and Galerkin weighted residual method. For the particular example considered in his paper, the finite difference solution appeared to be stable, even for oscillations involving angular rotations at the ends of the beam of the order of magnitude of $80^{\circ}$. Furthermore, he found that the Galerkin approximate solution was in closer agreement with the finite difference solution than the perturbation solution. Raju et al. 5 studied free flexural vibrations of a simply-supported beam when a compatible longitudinal or inplane mode was coupled with the fundamental flexural mode. The Rayleigh-Ritz method was employed. The results showed that the effects of longitudinal displacement and inertia were to reduce the nonlinearity in the flexural frequency-amplitude 
relationship. Tseng and Dugundji ${ }^{6}$ investigated a straight beam with fixed ends excited by a periodic motion at its supporting base in a direction normal to the beam span. By using Galerkin's method, the governing partial differential equation was reduced to the well-known Duffing equation. The harmonic balance method was applied to solve the Duffing equation. Pandalai ${ }^{7}$ investigated the case of straight beams, irrespective of the boundary conditions, the nonlinear was found to be of the hardening type. He further concluded that only the hardening type can be existed. Later, Atluri ${ }^{8}$ showed that there were some cases for which the softening type nonlinearity is possible. He investigated the large amplitude transverse vibration of a hinged bar with one end of the beam free to move longitudinally. The equation was solved by the perturbation procedure of multiple-time scales. The calculated results showed that the predominant nonlinear effect was due to longitudinal inertia which was of the softening Duffing type. This result was in contrast to the earlier analyses where a hardening nonlinearity had been predicted when the only nonlinearity considered was the effect of average midplane stretching due to the out-of-plane deflection.

Through the foregoing studies, the general features of the nonlinear response of beams under harmonic excitation seem to have been largely clarified. However, most of the actual calculations are based on a one-term approximation for the spatial function while the interactions between the modes with amplitude are not addressed. Corresponding to this phenomena, the effect of multiple modes on beam response is needed. Because of the complexity in the formulation, there are very few investigations on multiple-mode analysis in the li tera ture. 
McDonald $d^{9}$ apparently was the first to consider modal interactions. The considered investigation was the vibration of a uniform beam with hinged ends which were restrained. The beam was subjected to a concentrated lateral force at the mid-span and then released from rest at the deflected position. The nonlinear effect in this investigation was produced by the axial stretching of the beam. By assuming a multiple-mode expansion corresponding to the deflected position, the elliptic function procedure was performed to evaluate the coefficients related to the participation of each mode. Bennett and Eisley 10 investigated the steady-state free and forced responses and stability for large amplitude nonlinear vibration of a beam with clamped ends. The general equations for the response and stability were derived. By applying Galerkin's method, a set of nonlinear ordinary differential equations was obtained. The solution of forced vibration was evaluated by the method of harmonic balance. Later, Bennett 11 considered the problem involved the ultraharmonic response of a simply supported beam. Tseng and Dugundji12 also used a multiple-mode expansion in considering the forced response of a clamped beam about its buckled configuration. The buckled beam was excited by the harmonic motion at its supporting base. By using Galerkin's method, the governing partial differential equation reduced to a modified Duffing equation which was solved by the harmonic balance method. Srinivasan 13 solved free and forced responses of beams undergoing moderately large amplitude steady-state oscillations by the averaging method of Ritz. The application of Ritz's method to solve the governing nonlinear partial differential equation, yielded nonlinear algebraic equations instead of nonlinear ordinary differential equations. To solve these 
nonlinear algebraic equations, the Newton's method or bigradient matrix method had to be employed. The method was shown by assuming the first two symmetric modes of the linear system for the deflection of beam. It was clear that the method yielded as many simultaneous nonlinear algebraic equations as the number of modes included. Nayfeh et al.14 proposed a numerical-perturbation method for the determination of nonlinear forced response of beams. The deflection curve of the beam was represented with a multiple-mode expansion in terms of the linear modes. Then the temporal problem was solved by the method of multiple scales, and internal resonances was also considered. Van Dooren and Bouc ${ }^{15}$ considered the nonlinear transverse vibrations of a uniform beam with ends restrained and forced transversely by a two-mode function which was harmonic in time. A simply supported beam was considered by the two-mode approach. Approximate solutions were found by using Urabe's numerical method applied to Galerkin's procedure and by an analytical harmonic balance-perturbation method. The existence of subharmonic response of order $1 / 3$ and harmonic response in the sub-harmonic region of the forcing function was proved. Takahashic ${ }^{16}$ analyzed the inextensible clamped-free and free-free beams by using Galerkin's method and the harmonic balance method. Yamaki and Mori ${ }^{17}$ investigated nonlinear forced vibrations of a clamped beam under uniformly distributed periodic lateral loading with the effects of both initial deflection and initial axial displacement taken into consideration. The problem was first reduced to that of a finite degree-of-freedom system with the Galerkin procedure, the steady-state solutions which were obtained by applying the harmonic balance method. Actual calculation was carried out for the three degree-of-freedom system with symmetric 
modes. Yamaki et al. ${ }^{18}$ also performed experiments to compare to the analytic results. The test results were reported in the root-meansquare of deflection instead of the actual deflection of the beam.

Generally, the classical approach to solve nonlinear vibrations of a beam is to start with the so-called assumed mode shape. By employing the Galerkin's method, the governing nonlinear partial differential equation of motion is reduced to a system of nonlinear ordinary differential equations. The elliptic function, perturbation method, or numerical methods, can then be employed to solve the problem.

In practice, many optimum or minimum-weight designed structures are complex. Because of the versatility of the finite element method, it is more suitable to use this method to analyze complex structures. Mej ${ }^{19}$ investigated nonlinear vibration of beams by matrix displacement method. Nonlinear free vibrations of various boundary conditions were investigated and good agreements were obtained between the finite element method and other numerical methods. Rao et al. 20 studied the large amplitude free oscillations of beams and orthotropic circular plates. Their finite element formulation was based on an appropriate linearization of the nonlinear strain-displacement relations. Simply supported and clamped beams were investigated. Comparison of their results with the earlier work confirmed the reliability and effectiveness of the linearization of the strain-displacement relations. Reddy and Singh ${ }^{21}$ investigated the large-deflection analysis of thin elastic curved beams by conventional and mixed finite element methods. The conventional finite element method was based on the total potential energy expression, whereas the mixed method was based on a Reissner-type variational statement and involved the bending moments and 
deflections as primary dependent variables. From their result, it appeared that in general the mixed method yielded more accurate results. Recently, Mei and Decha-Umphai $22,23,24$ developed the harmonic force matrix for solving nonlinear forced vibrations of beams and plates by finite element method. By employing the linearizing method ${ }^{25}$ and socalled "single-mode" approach, the frequency-amplitude-force relations were obtained. There are very few attempts to solve nonlinear vibrations of beam using finite element method with multiple-mode expansion. Busby and Weingarten ${ }^{26}$ investigated beams of simply supported and clamped boundary conditions. Their finite element technique was performed only to obtain the nonlinear differential equations of the straight beam and the method of averaging was then used to obtain an approximate solution. Cheung and $\mathrm{Lau}^{27}$ investigated the two-mode nonlinear vibration of beams. The essence of their method could be regarded as an incremental harmonic balance method associated with a finite strip procedure in the time-space domain. Unfortunately, the works reported in References 26 and 27 could not be exactly classified as finite element method.

The accuracy of the theoretical predictions would not be completed unless the experimental studies had been compared. Bennett and Eisley 10 performed the experiment of a clamped beam to compare with their theoretical results. Tseng and Dugundji ${ }^{6}$ conducted the experiment of a straight beam with fixed ends which was excited by the periodic motion of $i$ ts supporting base in a direction normal to the beam span. All of these two experiments were found to compare favorably with the corresponding theoretical predictions. However, these experiments were carried out with special kinds of excitations, eg. supporting base 
excitation. Yamaki et al. 18 performed the experimental studies of a clamped beam under a uniformly distributed periodic load. Besides the reasonable agreement with the theoretical predictions, 17 their experimental results seem to provide effective data facilitating further theoretical analyses.

It is clear that a substantial amount of literature exists on nonlinear vibrations of beams. Sathyamoorthy 28,29 published two excellent survey articles, one which dealt with literature concerning classical nonlinear methods, and another with the finite element method.

Through the foregoing studies, the general features of the nonlinear free and forced vibrations of beams seem to have been largely clarified. However, modern structures are complex and the more accurate theoretical predictions are preferred, therefore, the multiple-mode approach has to be considered in the formulation of nonlinear vibration problems. Since the evolution of digital computers, the finite element method has become widely used to solve many types of complex structures. It is the purpose of this research to extend the finite element method to multiple-mode nonlinear vibrations.

In this thesis research, multiple-mode nonlinear free and forced vibrations of beams using finite element method are presented. Both out-of-plane deflection and inplane displacement are included in the formulation. The classical method is provided in Chap. 2 to review the concepts of nonlinear vibrations. In Chap. 3, the finite element formulation is presented in detail. The nonlinear stiffness matrices using the linearizing method ${ }^{25}$ are derived. The harmonic force matrix for multiple-mode approach is derived for both uniformly distributed and 
concentrated forces. In Chap. 4, the solution procedure of multiplemode nonlinear vibrations by finite element method is presented. In Chap. 5, beams with various out-of-plane and inplane boundary conditions are investigated. The definition of inplane boundary condition is also explained. The relations of frequency and amplitude for various boundary conditions and loads are tabulated and plotted. Results are also compared to other classical or experimental results whenever available. The convergence criteria are also studied. Chapter 6 gives the concluding remarks. 


\section{Chapter 2}

\section{CLASSICAL FORMULATIONS}

In this chapter, the mathematical formulations of the classical method are expressed. Equations of motion for an isotropic beam are presented. The characteristic equations are provided by performing the Galerkin's method. For single-mode approach, the frequency-amplitude relation is shown in a simple closed-form solution which could not be done for the multiple-mode approach. For multiple-mode approach, the general formulation is shown to provide for better understanding in the multiple-mode formulation. All of these formulations are performed in detail.

\subsection{Classical Method}

In general, nonlinear forced vibration of a beam is solved by the assumed mode method. By employing the Galerkin's method, the assumed mode shape is substituted into the governing equation of motion, then the integration is performed over spatial domain. The characteristic equations are obtained. The numerical time integration or other numerical method is needed for solving the frequency-amplitude relations. Both single and multiple-mode approaches are shown in the formulations. Because of the simplicity of single-mode approach, this approach is shown first to provide some concepts which later is extended to the multiple-mode formulation. 


\subsection{Single-Mode Approach}

The classical method for single-mode approach is straight forward. The frequency-amplitude relation exists in a simple closedform relation which could not be done for multiple-mode approach. The formulation for single-mode approach is as follows.

Assume that a uniform beam with cross sectional area $\bar{A}$, moment of inertia $I$ and length $L$ is subjected to a uniformly distributed periodic lateral load $F(x, t)$ as shown in Fig. 1. In this figure, a clamped beam is shown for simplicity. The deflection is denoted by $w(x, t)$. With the assumption that axial displacements at both ends are zero (immovable inplane displacement), the basic governing equation of motion for the nonlinear bending forced vibration of a beam is found to be

$$
\rho \bar{A} \ddot{w}+E I w_{x x x x}-N w_{x x}-F(x, t)=0
$$

where

$$
N=\frac{E \bar{A}}{2 L} \int_{0}^{L}(w, x)^{2} d x
$$

where $\rho$ and $E$ are mass density and Young's modulus, respectively. The subscript $x$ following a comma denotes differentiation with respect to $x$ and a dot denotes differentiation with respect to time $t$.

For single-mode approach, the deflection is assumed as

$$
w(x, t)=\phi(x) g(t)
$$

where $\phi(x)$ represents the normal mode of linear free vibration which satisfies the boundary conditions for the case in consideration, and the modal amplitude $g(t)$ is an unknown function of time. 
$F_{0} \cos \omega t$

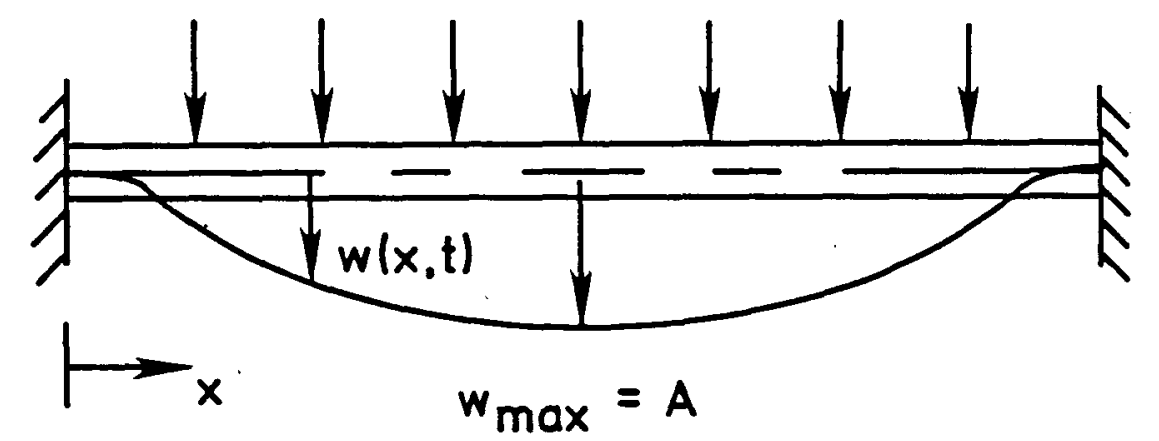

Fig. 1 Geometry of a clamped beam 
Using the foregoing expression for $w$, the Galerkin's method can be applied to Eq. (2.1), which leads to

$$
\int_{0}^{L}[E q .(2.1)] \phi(x) d x=\text { Residual } \cong 0 \text {. }
$$

Equation (2.4) can be expressed as

$$
\begin{aligned}
& {\left[\rho \bar{A} \int_{0}^{L} \phi^{2} d x\right] \ddot{g}+\left[E I \int_{0}^{L} \phi \text { sxxx }_{x x} \phi d x\right] g .} \\
& -\left[N \int_{0}^{L} \phi_{x x} \phi d x\right] g-F(t) \int_{0}^{L} \phi d x=0 .
\end{aligned}
$$

Equation (2.5) can be rewritten in the form as

$$
\begin{gathered}
\rho \bar{A} \ddot{g}+\left[E I \int_{0}^{L} \phi_{x x x x} \phi d x\right] g / \int_{0}^{L} \phi^{2} d x \\
-\left[N \int_{0}^{L} \phi_{x x} \phi d x\right] g / \int_{0}^{L} \phi^{2} d x-F(t) \int_{0}^{L} \phi d x / \int_{0}^{L} \phi^{2} d x=0 .
\end{gathered}
$$

By substituting Eq. (2.3) into Eq. (2.2), the inplane force $N$ can be expressed as

$$
N=\left[\frac{E \bar{A}}{2 L} \int_{0}^{L}(\phi, x)^{2} d x\right] g^{2}
$$

By using this value of N, Eq. (2.7), in conjunction with Eq. (2.6), the characteristic equation is obtained in the form as

$$
m \ddot{g}+k g+\bar{k} g^{3}-c F(t)=0
$$

where $m, k$ and $\bar{k}$ are the mass, linear stiffness and nonlinear stiffness terms, respectively. The values of $m, k$ and $\bar{k}$ can be expressed as 


$$
\begin{gathered}
m=\rho \bar{A} \\
k=E I \int_{0}^{L} \phi_{x x x x} \phi d x / \int_{0}^{L} \phi^{2} d x \\
\bar{k}=\frac{E \bar{A}}{2 L} \int_{0}^{L}\left(\phi_{0}\right)^{2} d x \int_{0}^{L} \phi_{x x} \phi d x / \int_{0}^{L} \phi^{2} d x .
\end{gathered}
$$

The value of constant $c$ is expressed as

$$
c=\int_{0}^{L} \phi d x / \int_{0}^{L} \phi^{2} d x \text {. }
$$

The characteristic equation, Eq. (2.8), can be written as

$$
m \ddot{g}+k g+\bar{k} g^{3}-P(t)=0
$$

where $P(t)$ is the force term which is expressed as

$$
P(t)=c F(t)
$$

The characteristic equation, Eq. (2.13), can be solved for the frequency-amplitude-force relation in a closed-form solution by various approximate methods. It should be pointed out that many of these approximate methods yield the same closed-form solution which can be classified as a standard form. Because of the simplicity of the following method, it is chosen to be shown in depth for the derivation of the closed-form solution. This method is based on omitting the nigher harmonic term.

To obtain the frequency-amplitude-force relation in closed-form solution, $g(t)$ is specified as

$$
g(t)=A \cos (\omega t)
$$

where $A$ is the amplitude of deflection of the beam and $\omega$ is nonlinear frequency. The nonlinear term, $g^{3}(t)$, is expressed as 


$$
g^{3}(t)=A^{3} \cos ^{3}(\omega t)
$$

By expanding $\cos ^{3}(\omega t)$, it can be written as

$$
\cos ^{3}(\omega t)=\frac{3}{4} \cos (\omega t)+\frac{1}{4} \cos (3 \omega t) .
$$

By neglecting the higher harmonic term, $\cos (3 \omega t)$, the approximation of $\cos ^{3}(\omega t)$ can be written as

$$
\cos ^{3}(\omega t) \cong \frac{3}{4} \cos (\omega t) .
$$

By substituting Eq. (2.18) into Eq. (2.16), the nonlinear term is expressed as,

$$
g^{3}(t)=\frac{3}{4} A^{3} \cos (\omega t)
$$

The force term, $P(t)$, is written as,

$$
P(t)=P_{0} \cos (\omega t)
$$

and by Eq. (2.14),

$$
P_{0}=C F_{0}
$$

and

$$
F(t)=F_{0} \cos (\omega t)
$$

where $F_{0}$ is force intensity which has the dimension as force per unit length.

By substituting Eqs. (2.15), (2.19) and (2.21) into Eq. (2.13), the frequency-amplitude-force relation can be shown as

$$
\begin{aligned}
& -\omega^{2} m A \cos (\omega t)+k A \cos (\omega t)+\frac{3}{4} \bar{k} A^{3} \cos (\omega t) \\
& -P_{0} \cos (\omega t)=0 .
\end{aligned}
$$

Equation (2.23) can be rewritten in the closed-form solution as 


$$
\omega^{2}=\omega_{L}^{2}+\frac{3}{4} \beta A^{2}-P_{0} / A
$$

where

$$
\begin{aligned}
\omega_{L}^{2} & =k / m \\
\beta & =\bar{k} / m .
\end{aligned}
$$

Equation $(2.24)$ is the standard closed-form relation between frequency and amplitude and force. $\omega_{L}$ is defined as linear frequency which has the dimension as radian per second.

\subsection{Multiple-Mode Approach}

The classical method for multiple-mode approach follows the same path as single-mode approach. But the multiple-mode approach could not yield the simple closed-form frequency-amplitude-force relation, thus, numerical integration or other approxima te method is needed.

The general formulation of multiple-mode approach is as follows,

$$
w(x, t)=\sum_{i=1}^{n} \phi_{i}(x) g_{j}(t)
$$

where $\phi_{j}(x)$ is the $i$-th normalized linear mode shape with maximum of unity, and $g_{j}(t)$ is the time function. The total number of modes in consideration is $n$.

The time function $g_{j}(t)$ can be expressed as

$$
g_{j}(t)=A_{i} \cos (\omega t)
$$

where $A_{j}$ is the amplitude of $i$-th mode shape. By using the assumed expression of w, Eq. (2.27), the Galerkin's method can be applied to Eq. (2.1) as follows: 


$$
\begin{aligned}
\int_{0}^{L}\left[\text { Eq. (2.1)] } \phi_{i}(x) d x\right. & =\text { Residua } 1 \cong 0 \\
i & =1,2 \ldots, n .
\end{aligned}
$$

By substituting Eq. (2.27) into Eq. (2.2), the axial force $N$ is expressed as

$$
\left.N=\frac{E \bar{A}}{2 L} \int_{0}^{L} \sum_{i=1}^{n} \phi_{i, x} g_{i}\right]^{2} d x
$$

By substituting Eq. (2.30) into Eq. (2.29), the following set of nonlinear ordinary differential equations are obtained:

$$
m_{i} \ddot{g}_{j}+k_{i} g_{j}+\sum_{j=1}^{n} \sum_{r=1}^{n} \sum_{s=1}^{n} \bar{k}_{i j r s} g_{j} g_{r} g_{s}
$$

where

$$
=p_{i}(t) \quad i=1,2, \cdots, n
$$

$$
m_{i}=\rho \bar{A}
$$

$$
k_{i}=E I \int_{0}^{L} \phi_{i, x x x x} \Phi_{i} d x / \int_{0}^{L} \phi_{i}^{2} d x
$$

$$
\begin{gathered}
\bar{k}_{i j r s}=\frac{E \bar{A}}{2 L} \frac{\int_{j, x}^{L} \phi_{r, x} d x \int_{0}^{L} \phi_{s, x x} \phi_{i} d x}{\int_{0}^{L} \phi_{i}^{2} d x} \\
P_{j}(t)=\int_{0}^{L} F(x, t) \phi_{i} d x / \int_{0}^{L} \phi_{i}^{2} d x .
\end{gathered}
$$

The set of nonlinear ordinary differential equations shown by Eq. (2.31) is the set of characteristic equations for nonlinear forced vibration. 
In general, the number of characteristic equations is the same as the number of mode shapes which are included in the assumed deflection shape, Eq. (2.27). These characteristic equations are highly nonlinear and coupled, thus, it is very tedious to solve for the steady-state solution. One way to obtain the frequency-amplitude-force relation is by performing numerical integration, e.g., Runge-Kutta method.

To clarify the method, a two-mode approach is performed as follows:

$$
w(x, t)=\sum_{i=1}^{2} \phi_{i}(x) g_{i}(t) .
$$

The deflection shape $w(x, t)$ is assumed as the combination of two modes. In this case, $n$ is equal two. The value of $N, E q .(2.30)$, can be expressed as

$$
\begin{array}{r}
N=\frac{E \bar{A}}{2 L}\left[\left(\int_{0}^{L} \phi_{1, x}^{2} d x\right) g_{1}^{2}+\left(\int_{0}^{L} \phi_{2, x}^{2} d x\right) g_{2}^{2}\right. \\
\left.+\left(2 \int_{0}^{L} \phi_{1, x} \phi_{2, x} d x\right) g_{1} g_{2}\right]
\end{array}
$$

By using Eqs. (2.36) and (2.37), the set of characteristic equations, Eq. (2.31), can be obtained as

$$
\begin{aligned}
& m_{1} \ddot{g}_{1}+k_{1} g_{1}+\bar{k}_{1111} g_{1}^{3}+\bar{k}_{1112} g_{1}^{2} g_{2}+\bar{k}_{1122} g_{1} g_{2}{ }^{2} \\
&+\bar{k}_{1222} g_{2}^{3}=p_{1}(t) \\
& m_{2} \ddot{g}_{2}+k_{2} g_{2}+\bar{k}_{2111} g_{1}^{3}+\bar{k}_{2112} g_{1}^{2} g_{2}+\bar{k}_{2122} g_{1} g_{2}^{2} \\
&+\bar{k}_{2222} g_{2}^{3}=p_{2}(t)
\end{aligned}
$$


20

where

$$
\begin{aligned}
& m_{1}=\rho \bar{A} \\
& k_{1}=E I \int_{0}^{L} \phi_{1, x x x x} \phi_{1} d x / \int_{0}^{L} \phi_{1}^{2} d x \\
& \bar{k}_{1111}=\frac{E \bar{A}}{2 L} \int_{0}^{L} \phi_{1, x}^{2} d x \int_{0}^{L} \phi_{1, x x} \phi_{1} d x / \int_{0}^{L} \phi_{1}^{2} d x \\
& \bar{k}_{1112}=\frac{E \bar{A}}{2 L} \int_{0}^{L} \phi_{1, x}^{2} d x \int_{0}^{L} \phi_{2, x x} \phi_{1} d x / \int_{0}^{L} \phi_{1}^{2} d x \\
& \bar{k}_{1122}=\frac{E \bar{A}}{2 L} \int_{0}^{L} \phi_{1, x} \phi_{2, x} d x \int_{0}^{L} \phi_{2, x x} \phi_{1} d x / \int_{0}^{L} \phi_{1}^{2} d x \\
& \bar{k}_{1222}=\frac{E \bar{A}}{2 L} \int_{0}^{L} \phi_{2, x}^{2} d x \int_{0}^{L} \phi_{2, x x} \phi_{1} d x / \int_{0}^{L} \phi_{1}^{2} d x \\
& P_{1}(t)=\int_{0}^{L} F(x, t) \phi_{1} d x / \int_{0}^{L} \phi_{1}^{2} d x \\
& m_{2}=\rho \bar{A} \\
& k_{2}=E I \int_{0}^{L} \phi_{2, x x x x} \phi_{2} d x / \int_{0}^{L} \phi_{2}^{2} d x
\end{aligned}
$$




$$
\begin{aligned}
& \bar{k}_{2111}=\frac{E \bar{A}}{2 L} \int_{0}^{L} \phi_{1, x}^{2} d x \int_{0}^{L} \phi_{1, x x} \phi_{2} d x / \int_{0}^{L} \phi_{2}^{2} d x \\
& \bar{k}_{2112}=\frac{E \bar{A}}{2 L} \int_{0}^{L} \phi_{1, x}^{2} d x \int_{0}^{L} \phi_{2, x x} \phi_{2} d x / \int_{0}^{L} \phi_{2}^{2} d x \\
& \bar{k}_{2122}=\frac{E \bar{A}}{2 L} \int_{0}^{L} \phi_{1, x} \phi_{2, x} d x \int_{0}^{L} \phi_{2, x x} \phi_{2} d x / \int_{0}^{L} \phi_{2}^{2} d x \\
& \bar{k}_{2222}=\frac{E \bar{A}}{2 L} \int_{0}^{L} \phi_{2, x}^{2} d x \int_{0}^{L} \phi_{2, x x} \phi_{2} d x / \int_{0}^{L} \phi_{2}^{2} d x .
\end{aligned}
$$

The steady-state response for a two-mode nonlinear vibration problem can be obtained by employing the Runge-Kutta method for solving the nonlinear coupled characteristic equations, Eqs. (2.38) and (2.39). 


\section{Chapter 3}

\section{FINITE ELEMENT FORMULATION}

In this chapter, the formulation of a finite element method is presented. The expressions for strain-displacement relation, kinetic energy and potential energy are provided. The linearizing function for deriving nonlinear stiffness matrices is defined. The inplane displacement and lateral deflection are expanded in the cubic order. Furthermore, the derivation of harmonic force matrix is performed.

\subsection{Strain and Curvature-Displacement Relations}

The strain-displacement relation of a beam element shown in Fig. 2 is given by

$$
\varepsilon_{x}=u_{x}+\frac{1}{2} w_{x}^{2}
$$

where $\varepsilon_{x}$ is the strain in $x$-direction of beam, $u$ is the inplane displacement and $w$ is the lateral deflection. The curvaturedisplacement relation is defined as

$$
\psi_{x}=w_{x x}
$$

where $\psi_{x}$ is the curvature. The total strain, $\varepsilon$, is defined as

$$
\varepsilon=u_{x}+\frac{1}{2} w_{x x}^{2}-z w_{x x} \text {. }
$$




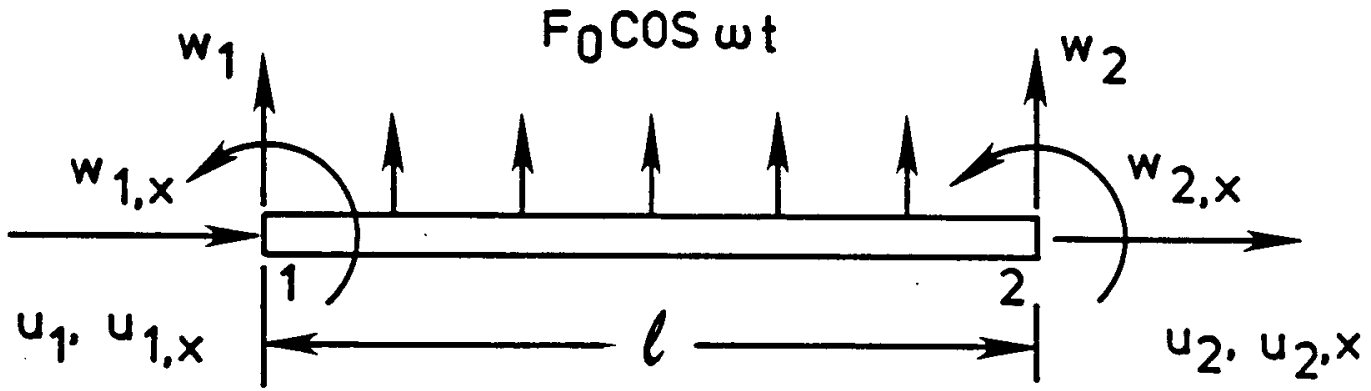

Fig. 2 Beam Element 


\subsection{Kinetic and Strain Energies}

The kinetic energy of a beam element is given by

$$
T=\frac{1}{2} \rho \int_{0}^{l}\left(\dot{u}^{2}+\dot{w}^{2}\right) d x
$$

where $\rho$ is mass per unit length and $l$ is element length. The kinetic energy can be separated into two parts as

$$
T=T_{s}+T_{b} \text {. }
$$

The kinetic energy due to mid-plane stretching $T_{s}$ is defined as

$$
\mathrm{T}_{\mathrm{s}}=\frac{1}{2} \rho \int_{0}^{l} \dot{u}^{2} \mathrm{dx}
$$

and the kinetic energy due to bending $T_{b}$ is defined as

$$
T_{b}=\frac{1}{2} \rho \int_{0}^{l} \dot{w}^{2} d x \text {. }
$$

The strain energy of a beam element is given by

$$
U=\frac{1}{2} \int_{0}^{l}\left(E \bar{A} \varepsilon_{x}^{2}+E I \phi_{x}^{2}\right) d x
$$

where $E$ is Young's modulus, $\bar{A}$ is the cross-sectional area of beam, and I is the moment of inertia. By substituting Eqs. (3.1) and (3.2) into Eq. (3.8), the relation between strain energy and displacements can be written as

$$
\begin{aligned}
U=\frac{1}{2} \int_{0}^{l} E \bar{A}\left[u_{,}^{2}+2 u, x\right. & \left.\left(\frac{1}{2} w, \frac{2}{x}\right)+\left(\frac{1}{2} w, \frac{2}{x}\right)^{2}\right] d x \\
& +\frac{1}{2} \int_{0}^{l} E I w_{x x}^{2} d x .
\end{aligned}
$$


The strain energy $U$ can be separated into two parts, namely, linear strain energy $U_{L}$ and nonlinear strain energy $U_{N L}$.

$$
U=U_{L}+U_{N L}
$$

The linear strain energy for Eq. (3.10) is expressed as

$$
U_{L}=\frac{1}{2} \int_{0}^{l} E \bar{A} u_{0}^{2} d x+\frac{1}{2} \int_{0}^{l} E I w_{x x}^{2} d x
$$

Similarly, the nonlinear strain energy for Eq. (3.10) is expressed as

$$
U_{N L}=\frac{1}{2} \int_{0}^{l} E \bar{A}\left[2 u_{x}\left(\frac{1}{2} w, \frac{2}{x}\right)+\left(\frac{1}{2} w, \frac{2}{x}\right)^{2}\right] d x \text {. }
$$

\subsection{Displacement Functions}

The displacement functions are chosen to be in cubic order as follows:

$$
w=a_{1}+a_{2} x+a_{3} x^{2}+a_{4} x^{3}
$$

and

$$
u=a_{5}+a_{6} x+a_{7} x^{2}+a_{8} x^{3}
$$

The generalized coordinates $a_{1}, \ldots, a_{8}$ can be written in vector form as

$$
\{a\}^{\top}=\left[\begin{array}{llllllll}
a_{1} & a_{2} & a_{3} & a_{4} & a_{5} & a_{6} & a_{7} & a_{8}
\end{array}\right]
$$

and the element nodal displacement, Fig. 2, are defined as

$$
\{\delta\}^{\top}=\left[\begin{array}{llllllll}
w_{1} & \theta_{1} & w_{2} & \theta_{2} & u_{1} & \alpha_{1} & u_{2} & \alpha_{2}
\end{array}\right]
$$


where $\theta_{j}$ and $\alpha_{i}$ are the differentiation with respect to $x$ of $w_{j}$ and $u_{i}$ at node $i$, respectively. The generalized coordinates in Eq. (3.15) can be written as

$$
\{a\}=[T]\{\delta\}
$$

where $[T]$ is a transformation matrix.

The displacements $u$ and $w$ including their derivatives can be expressed in terms of element nodal displacements as

$$
\begin{aligned}
& u=\left[\begin{array}{llllllll}
0 & 0 & 0 & 0 & 1 & \times & x^{2} & x^{3}
\end{array}\right]\{a\} \\
& =[B][T]\{\delta\} \\
& u_{x_{x}}=\left[\begin{array}{llllllll}
0 & 0 & 0 & 0 & 0 & 1 & 2 x & 3 x^{2}
\end{array}\right]\{a\} \\
& =[C][T]\{\delta\} \\
& w=\left[\begin{array}{lllllllll}
1 & x & x^{2} & x^{3} & 0 & 0 & 0 & 0
\end{array}\right]\{a\} \\
& =[D][T]\{\delta\} \\
& w_{x_{x}}=\left[\begin{array}{lllllllll}
0 & 1 & 2 x & 3 x^{2} & 0 & 0 & 0 & 0
\end{array}\right]\{a\} \\
& =[E][T]\{\delta\} \\
& w_{x x}=\left[\begin{array}{llllllll}
0 & 0 & 2 & 6 x & 0 & 0 & 0 & 0
\end{array}\right]\{a\} \\
& =[G][T]\{\delta\}
\end{aligned}
$$




\subsection{Linearizing Function}

The linearizing function is defined as 5,25

$$
f=\frac{1}{2} w \cdot x
$$

By substituting Eq. (3.21) into (3.23), the linearizing function can be expressed as

$$
f=\frac{1}{2}[E][T]\{\delta\}
$$

This linearizing function $f$ is assumed to be constant in each element. The main advantage of using linearizing function is shown in the following sections.

\subsection{Element Equations of Motion for Nonlinear Free Vibration}

The nonlinear free vibration is the backbone of the investigation of steady-state response. The equations of motion can be derived by applying Lagrange's equations as follows.

From Eqs. (3.6) and (3.18), the expression of kinetic energy due to mid-plane stretching $T_{s}$ can be written in matrix form as

$$
\begin{aligned}
T_{s} & =\frac{1}{2}\{\dot{\delta}\}^{T}[T]^{T} \int_{0}^{l} \rho[B]^{T}[B] d x[T]\{\dot{\delta}\} \\
& =\frac{1}{2}\{\dot{\delta}\}^{T}\left[m_{s}\right]\{\dot{\delta}\}
\end{aligned}
$$

where $\left[m_{s}\right]$ is the element mass matrix due to inplane displacement function and is expressed as 


$$
\left[m_{S}\right]=[T]^{T} \int_{0}^{l} \rho[B]^{T}[B] d x[T] .
$$

Similarly, from Eqs. (3.7) and (3.20) the expression of kinetic energy due to bending $T_{b}$ can be written as

$$
T_{b}=\frac{1}{2}\{\dot{\delta}\}^{\top}\left[m_{b}\right]\{\dot{\delta}\}
$$

where $\left[m_{b}\right]$ is the element mass matrix due to bending and is expressed as

$$
\left[m_{b}\right]=[T]^{T} \int_{0}^{l} \rho[D]^{T}[D] d x[T] .
$$

The total kinetic energy T, Eq. (3.5), can be expressed in matrix form as

$$
T=\frac{1}{2}\{\dot{\delta}\} \quad[m]\{\dot{\delta}\}
$$

where $[\mathrm{m}]$ is the element mass matrix and is expressed as

$$
[m]=\left[m_{s}\right]+\left[m_{b}\right]
$$

The linear strain energy $U_{L}$, Eq. (3.11), can be expressed in matrix form as

$$
U_{L}=\frac{1}{2}\{\delta\}^{\top}\left[k_{L}\right]\{\delta\}
$$

where $\left[k_{L}\right]$ is the element linear stiffness matrix. The element linear stiffness matrix $\left[k_{L}\right]$ can be separated into u-part $\left[k_{L S}\right]$ and $w$-part $\left[k_{L b}\right]$ as

$$
\left[k_{L}\right]=\left[k_{L S}\right]+\left[k_{L b}\right]
$$

where

$$
\left[k_{L S}\right]=[T]^{T} \int_{0}^{\ell} E \bar{A}[C]^{T}[C] d x[T]
$$




$$
\left[k_{L b}\right]=[T]^{T} \int_{0}^{l} E I[G]^{T}[G] d x[T]
$$

The nonlinear strain energy $U_{N L}$, Eq. (3.12), can be written by using the linearizing function $f$, Eq. $(3.23)$, as

$$
U_{N L}=\frac{1}{2} \int_{0}^{l} E \bar{A}\left[2 f u_{x}, w_{x}+f^{2} w_{x}^{2}\right] d x
$$

By substituting Eqs. (3.19) and (3.21) into Eq. (3.35), the nonlinear strain energy can be expressed in matrix form as

$$
U_{N L}=\frac{1}{2}\{\delta\}^{\top}\left[k_{N L}\right]\{\delta\}
$$

where $\left[k_{N L}\right]$ is the element nonlinear stiffness matrix and is expressed as

$$
\begin{aligned}
{\left[k_{N L}\right] } & =[T]^{T} \int_{0}^{l}\left\{E \bar{A} f\left[[C]^{\top}[E]+[E]^{\top}[C]\right]\right. \\
& \left.+E \bar{A} f^{2}[E]^{\top}[E]\right\} d x[T] .
\end{aligned}
$$

The linearizing function $f$ which is a constant for each element transforms the element nonlinear stiffness matrix $\left[k_{N L}\right]$ into the linear form as in Eq. (3.37). The strain energy U, Eq. (3.10), can be written as

$$
U=\frac{1}{2}\{\delta\}^{\top}[k]\{\delta\}
$$

where $[k]$ is the element stiffness matrix and is expressed as

$$
[k]=\left[k_{L}\right]+\left[k_{N L}\right] \text {. }
$$


The application of Lagrange's equation leads to the element nonlinear free vibration equation of motion as

$$
[m]\{\ddot{\delta}\}+\left[\left[k_{L}\right]+\left[k_{N L}\right]\right]\{\delta\}=0 \text {. }
$$

\subsection{Element Harmonic Force Matrix}

In Chap. 2, the equation of motion for nonlinear forced vibration in classical approach is expressed in Eq. (2.13) as

$$
m \ddot{g}+k g+\bar{k} g^{3}=P(t)
$$

when the forcing function $P(t)$ is a simple harmonic $P_{0} \cos (\omega t)$, an approximate solution of Eq. (3.41) is in the form of Eq. (2.24) as

$$
\omega^{2}=\omega_{L}^{2}+\frac{3}{4} \beta A^{2}-P_{0} / A \text {. }
$$

When the forcing function $P(t)$ is a simple elliptic function and expressed as

$$
\begin{aligned}
P(t) & =B^{\star} A \text { Cn }(\lambda t, \eta) \\
& =B^{*} g
\end{aligned}
$$

where $g$ is the Jacobian elliptic function and expressed as

$$
g=A \text { cn }(\lambda t, \eta)
$$

where $B^{*}$ is forcing amplitude factor, $\lambda$ is circular frequency of the Jacobian elliptic function and $\eta$ is modulus of the Jacobian elliptic function.

By expanding the elliptic forcing function into Fourier series then comparing the order of the magnitude of the various components, Hsu 30 concluded that the harmonic forcing function $P_{0} \cos (\omega t)$ is the first order approximation of the elliptic forcing function $B^{\star} A$ cn $(\lambda t, \eta)$. 
Also, the first order appoximation of the elliptic response of Eq. (3.41) yields the same frequency-amplitude-force relation of Eq. (3.42) which is the perturbation solution (standard form, Eq. (2.24)). To obtain the exact elliptic response of Eq. (3.41), the forcing function $P(t)$ in Eq. (3.43) is treated as a linear spring in the Duffing equation, Eq. (3.41).

$$
\begin{aligned}
& m \ddot{g}+k g+\bar{k} g^{3}=B^{*} g \\
& m \ddot{g}+\left(k-B^{\star}\right) g+\bar{k} g^{3}=0 .
\end{aligned}
$$

This linear spring force $B^{*} g$ possesses a potential energy as $B^{*} g^{2} / 2$. Similarly, the potential energy of a beam due to the uniform harmonic forcing function $F_{0} \cos \omega t$ can thus be approximated by

$$
V=\Sigma \frac{B^{*}}{2} \int_{0}^{l} w^{2} d x
$$

where the summation denotes the sum of all elements.

To find the value of $\mathrm{B}^{\star}$, the conclusion by $\mathrm{Hsu}^{30}$ is needed (Eq. (3.43)) as follows

$$
\begin{aligned}
P(t) & =B^{\star} g \\
& =B^{\star} A \text { cn }(\lambda t, \eta)
\end{aligned}
$$

so,

$$
P_{0} \cos (\omega t) \cong B^{\star} A \text { cn }(\lambda t, \eta) \text {. }
$$

By using Hsu's conclusion, the harmonic function $\cos (\omega t)$ is the first order approximation of the elliptic function $\mathrm{cn}(\lambda t, \eta)$, thus,

$$
\cos (\omega t) \cong c n(\lambda t, n) \text {. }
$$


By using the relation of Eq. (3.48), substitutes into Eq. (3.47), the relation of $B^{*}$ can be expressed as

$$
B^{*}=P_{0} / A \text {. }
$$

From Eq. (2.21), the relation of $p_{0}$ is expressed as follows

$$
P_{0}=c F_{0}
$$

where the constant $c$ is expressed in Eq. (2.12). The constant $c$ can be interpreted as the ratio of area under mode shape and square of mode shape. And the nonlinear mode shape in multiple-mode approach is assumed to be sum of linear modes, thus, the deflection $w(x, t)$ can be written as

$$
w(x, t)=\phi^{\star}(x) g^{*}(t)
$$

where $\phi^{\star}(x)$ is normalized nonlinear mode and $g^{\star}(t)$ is time function, thus,

$$
\phi^{\star}(x)=\frac{1}{A} \sum_{i=1}^{n} A_{i} \phi_{i}(x)
$$

where $A_{j}$ and $\phi_{j}(x)$ are the amplitude of $i$-th mode shape and the $i$-th normalized linear mode shape, respectively. By using Eq. (3.52) and the definition of $c$ in Eq. (2.12), in general, the expression of $c$ for simple harmonic force is expressed as

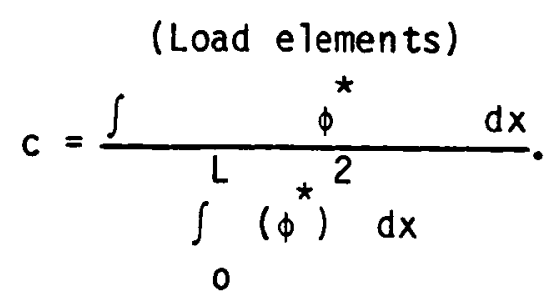


Thus, for the uniformly distributed force over the entire beam, the value of $c$ is expressed as

$$
c=\frac{\int_{0}^{L} \phi^{*} d x}{\int_{0}^{L}\left(\phi^{*}\right)^{2} d x} .
$$

In the finite element method, the concentrated force can be represented by the distributed force over a small length, thus, the value $c$ for concentrated can be expressed as

$$
c=\frac{\int_{a}^{b} \phi^{\star} d x}{\int_{0}^{L}\left(\phi^{\star}\right)^{2} d x}
$$

where $a$ and $b$ are coordinates of beam under that distributed force.

By using the Eq. (3.46), the element harmonic force matrix can be derived from

$$
V=\frac{B}{2} \int_{0}^{l} w^{2} d x
$$

where $B_{*}$ is expressed in Eq. (3.49). By substituting Eq. (3.20) into (3.56), the potential energy due to the uniform harmonic force can be expressed as

$$
\begin{aligned}
V & =\frac{B^{\star}}{2}\{\delta\}^{\top}[T]^{\top} \int_{0}^{\ell}[D]^{T}[D] d x[T]\{\delta\} \\
& =\frac{1}{2}\{\delta\}^{\top}[h]\{\delta\}
\end{aligned}
$$

where $[h]$ is the element harmonic force matrix and expressed as 


$$
[h]=B^{\star}[T]^{T} \int_{0}^{\ell}[D]^{T}[D] d x[T]
$$

By comparing Eq. (3.58) to Eq. (3.28) and using the expression of $\mathrm{B}^{*}$ and $P_{0}$, Eqs. (3.49) and (3.50), the harmonic force matrix can be written as

$$
[h]=\frac{C F_{0}}{A \rho}\left[m_{b}\right]
$$

where $c$ is a constant expressed in Eqs. (3.53), (3.54) or (3.55). It should be noted that the harmonic force matrix is a symmetrical matrix.

\subsection{Element Equations of Motion for Nonlinear Forced Vibration}

The application of Lagrange's equation leads to the equations of motion for nonlinear forced vibration of a beam element under harmonic forcing function. By using Eqs. (3.29), (3.38) and (3.57), the equations of motion are expressed as

$$
[\mathrm{m}]\{\ddot{\delta}\}+\left[\left[k_{L}\right]+\left[k_{N L}\right]-[h]\right]\{\delta\}=0
$$

where $[\mathrm{m}]$ is the element mass matrix in Eq. $(3.30),\left[k_{L}\right]$ is the element linear stiffness matrix in Eq. (3.32), $\left[k_{N L}\right]$ is the element nonlinear stiffness matrix in Eq. (3.37), and [h] is the element harmonic force matrix in Eq. (3.59). It should be noted that all these matrices are symmetric. 


\section{Chapter 4}

\section{SOLUTIONS PROCEDURES}

In this chapter, the solution procedures of finite element method are explained in detail. The solution procedures are divided into two major parts, namely, the small deflection part which is the linear solution, and the large amplitude part which is the nonlinear solution. Each part consists of minor steps which evaluate the element and system matrices. The iterative process for the large amplitude part is also explained. The convergence criteria are also provided and convergence characteristics are shown in figures. Finally, the computer flow-chart of the solution procedures is provided at the end of this chapter.

\subsection{Small Deflection Solution (Linear Solution)}

Linear solution is performed to evaluate the linear eigenvalues (linear frequencies) and linear eigenvectors (linear mode shapes). The combination of these linear mode shapes and amplitude for each mode is represented for multiple-mode approach which is later used in the nonlinear solution.

The application of Lagrange's equation leads to the equation of motion for linear free vibration of a beam element as

$$
[\mathrm{m}]\{\ddot{\delta}\}+\left[\mathrm{k}_{L}\right]\{\delta\}=0
$$


where $[m]$ and $\left[k_{L}\right]$ are the element mass and linear stiffness matrices as defined in Eqs. (3.30) and (3.32), respectively. The element mass matrices, $\left[m_{s}\right]$ and $\left[m_{b}\right]$ as defined in Eq. (3.30), can be evaluated from Eqs. (3.26) and (3.28), respectively. After all element mass and stiffness matrices are known, the equations of motion for the system can be assembled as

$$
[M]\{\ddot{\Delta}\}+\left[K_{L}\right]\{\Delta\}=0
$$

where $[M]$ and $\left[K_{L}\right]$ are the system mass and linear stiffness matrices, respectively. $\{\Delta\}$ is the eigenvector which consists of the vectors in term of $w$ and $w, x$, and $u$ and $u_{,} x^{*}$ This eigenvector $\{\Delta\}$ can be expressed as

$$
\{\Delta\}=\left\{\begin{array}{c}
\{\phi\} \\
\{\zeta\}
\end{array}\right\}
$$

where $\{\phi\}$ is the eigenvector related to $w$ and $w, x$, and $\{\zeta\}$ is the eigenvector related to $u$ and $u_{x_{x}}$. By using the bending part of Eq. (4.2), the system equations of motion for bending only can be expressed as

$$
\left[M_{b}\right]\{\ddot{\phi}\}+\left[K_{L b}\right]\{\phi\}=0
$$

where $\left[M_{b}\right]$ and $\left[K_{L b}\right]$ are the bending system mass and linear stiffness matrices which are related to Eqs. (3.28) and (3.34), respectively. Equation (4.4) can be rewritten as

$$
\omega_{L}^{2}\left[M_{b}\right]\left\{\phi_{L}\right\}=\left[K_{L b}\right]\left\{\phi_{L}\right\}
$$

where $\omega_{L}$ is the linear frequency (eigenvalue) and $\left\{\phi_{L}\right\}$ is the corresponding linear mode shape normalized to unity at the middle of beam. It should be pointed out that for each linear frequency, there is a corresponding linear mode shape, for example, the first linear 
frequency $\omega_{L 1}$ corresponds to $\left\{\phi_{L 1}\right\}, \omega_{L 2}$ corresponds to $\left\{\phi_{L 2}\right\}, \cdots$, and $\omega_{\operatorname{Ln}}$ corresponds to $\left\{\phi_{\operatorname{Ln}}\right\}$.

Through the foregoing procedure, the linear solution for free vibration of beam has been clarified. The linear frequencies; $\omega_{L 1}, \omega_{L 2}, \cdots, \omega_{L n}$ and the corresponding 1 inear mode shapes; $\left\{\phi_{L 1}\right\},\left\{\phi_{L 2}\right\}, \cdots,\left\{\phi_{L n}\right\}$ have been evaluated. These linear mode shapes will be used later for multiple-mode approach in the next section.

\subsection{Large Amplitude Solution (Nonl inear Solution)}

In this section, the multiple-mode nonlinear free and forced vibrations of beam by finite element method are presented. The iterative procedure and the convergence criteria are also included.

After the linear mode shapes have been determined (see Section 4.1 Small Deflection Solution), the nonlinear solution is performed as follows.

By using the first linear mode shape and the total amplitude at the middle of the beam, the deflection shape for the first iteration is expressed as

$$
\{\phi\}=A\left\{\phi_{L 1}\right\}
$$

By using Eq. (4.6), the deflection shape of each element $\{\delta\}$ can be found. By using $\{\delta\}$ and Eq. (3.24), the linearizing function, f, for each element can be determined. After the linearizing function has been determined, the element nonlinear stiffness matrix $\left[k_{N L}\right]$ for each element can be evaluated by using Eq. (3.37). The integration in 
Eq. (3.37) can be performed by the extended Simpson's rule for 20 intervals 32 .

The element stiffness matrix [k] and element mass matrix [m] can be determined by using Eqs. (3.39) and (3.30), respectively.

The element harmonic force matrix [h] can be determined by using Eq. (3.59). The constant $c$ in Eq. (3.59) is expressed in Eqs. (3.53), $(3.54)$ and $(3.55)$.

The application of Lagrange's equation leads to the element nonlinear forced vibration of beam under harmonic forcing function. This equation of motion is expressed as

$$
[m]\{\ddot{\delta}\}+[[k]-[h]]\{\delta\}=0 \text {. }
$$

Equation (4.7) can be rewritten as

$$
[m]\{\ddot{\delta}\}+\left[\left[k_{L}\right]+\left[k_{N L}\right]-[h]\right]\{\delta\}=0
$$

After all the element mass, stiffness and harmonic force matrices have been determined for each element, the equations of motion for the system can be assembled as

$$
[M]\{\ddot{\Delta}\}+\left[\left[K_{L}\right]+\left[K_{N L}\right]-[H]\right]\{\Delta\}=0
$$

where $\left[\mathrm{K}_{\mathrm{NL}}\right]$ and $[\mathrm{H}]$ are the system nonlinear stiffness and system harmonic force matrices, respectively. The system equations of motion, Eq. (4.9), can be reduced into the terms of $w$ and $w,_{x}$ by using Guyan's reduction technique 31 and the definition of $\{\Delta\}$ is defined in $E q$. (4.3). This reduced system equation of motion can be expressed as

$$
[R M]\{\ddot{\phi}\}+[R K]\{\phi\}=0
$$


where [RM] is the reduced system mass matrix and [RK] is the reduced system stiffness matrix. It should be noted that [RK] consists of not only the reduced system linear and nonlinear stiffness matrices but also the reduced system harmonic force matrix.

In the process of transformation Eq. (4.9) into Eq. (4.10) there exists the relation between the system deflection shape $\{\Delta\}$ and the reduced system deflection shape as 31

$$
\{\Delta\}=[T R F]\{\phi\}
$$

where $[T R F]$ is the transformation matrix.

By the definition of multiple-mode approach, the reduced system deflection shape $\{\phi\}$ is the combination of the linear mode shapes $\left\{\phi_{L}\right\}$ in Eq. (4.5) and their amplitudes. This reduced system deflection shape $\{\phi\}$ can be expressed as

$$
\{\phi\}=A_{1}\left\{\phi_{L 1}\right\}+A_{2}\left\{\phi_{L 2}\right\}+\cdots+A_{n}\left\{\phi_{L n}\right\}
$$

where $A_{i}$ is the amplitude of the $i$-th mode, $\left\{\phi_{L i}\right\}$ is the linear mode shape of the $i$-th mode and $n$ is the total number of modes. Equation (4.12) can be rewritten in a matrix form as

$$
\{\phi\}=\left[\begin{array}{llll}
\left\{\phi_{L 1}\right. & \left\{\phi_{L 2}\right\} & \cdots & \left\{\phi_{L n}\right\}
\end{array}\right]\left\{\begin{array}{c}
A_{1} \\
A_{2} \\
\vdots \\
A_{n}
\end{array}\right\}
$$

or

$$
\{\phi\}=\left[\phi_{0}\right]\left\{A_{0}\right\}
$$

where

$$
\left[\phi_{0}\right]=\left[\begin{array}{lll}
\left\{\phi_{L 1}\right\} & \left\{\phi_{L 2}\right\} & \cdots \cdots\left\{\phi_{L n}\right\}
\end{array}\right]
$$




$$
\left\{A_{0}\right\}=\left\{\begin{array}{c}
A_{1} \\
A_{2} \\
\vdots \\
A_{n}
\end{array}\right\}
$$

By using Eq. (4.14), Eq. (4.10) can be transformed to the norma? coordinates, $\left\{A_{0}\right\}$, and is expressed as

$$
\left[\phi_{0}\right]^{\top}[R M]\left[\phi_{0}\right]\left\{\ddot{A}_{0}\right\}+\left[\phi_{0}\right]^{\top}[R K]\left[\phi_{0}\right]\left\{A_{0}\right\}=0
$$

or

$$
\left[R M_{0}\right]\left\{\ddot{A}_{0}\right\}+\left[R K_{0}\right]\left\{A_{0}\right\}=0 .
$$

Equation (4.17) is in the form of an eigenvalue problem which can be expressed as

$$
\omega_{N L}^{2}\left[R M_{0}\right]\left\{A_{0}\right\}=\left[R K_{0}\right]\left\{A_{0}\right\}
$$

where $\omega_{N L}$ is the nonlinear frequency. By solving the eigenvalue problem, Eq. (4.18), the nonlinear frequency $\omega_{N L 1}$ and the eigenvector $\left\{A_{0}\right\}$ can be determined. After the eigenvector $\left\{A_{0}\right\}$ has been known, the amplitude ratios $\frac{A_{i}}{A_{1}} ; i=1,2, \cdots, n$ can be determined.

By the definition of multiple-mode approach, Eq. (4.12), the maximum deflection (amplitude) is the summation of amplitudes of all the modes. This can be expressed as

$$
A=\sum_{i=1}^{n} A_{i}
$$

or

$$
\frac{A}{A_{1}}=1+\sum_{i=2}^{n} \frac{A_{i}}{A_{1}}
$$

or 


$$
A_{1}=\frac{A}{1+\sum_{i=2}^{n} \frac{A_{i}}{A_{1}}} .
$$

The ratio $\frac{A_{i}}{A_{1}}$ is from Eq. (4.18) as mentioned before. The value of amplitude for $i-$ th mode, $A_{j}$, can be solved by

$$
A_{i}=\left(\frac{A_{i}}{A_{1}}\right) A_{1} ; i=2,3, \cdots, n \text {. }
$$

Through the foregoing procedure, the first iteration has been completed. The next iteration starts by using

$$
\{\phi\}=\sum_{i=1}^{n} A_{i}\left\{\phi_{L i}\right\}
$$

By using Eq. (4.23) instead of Eq. (4.6), the next iteration is performed from that point onward to obtain the improved nonlinear frequency $\omega_{N L 1}$ and $i$-th amplitude $A_{i}$. This iterative process can now be repeated until a convergence criterion (Section 4.3) is satisfied. It should be noted that the nonlinear stiffness matrix $\left[k_{N L}\right]$ and the harmonic matrix [h] are updated in each iterative process because of the changing of the values of $A_{i}$. The flow-chart of this solution procedure is shown in Fig. 3 .

\subsection{Convergence Criteria}

Three displacement convergence criteria proposed by Bergan and clough ${ }^{33}$ and a frequency convergence criterion are employed in the present study. The three displacement norms (criteria) are the modified absolute norm, the modified Euclidean norm and the maximum norm. The definitions of these three norms are given in the Appendix. The 


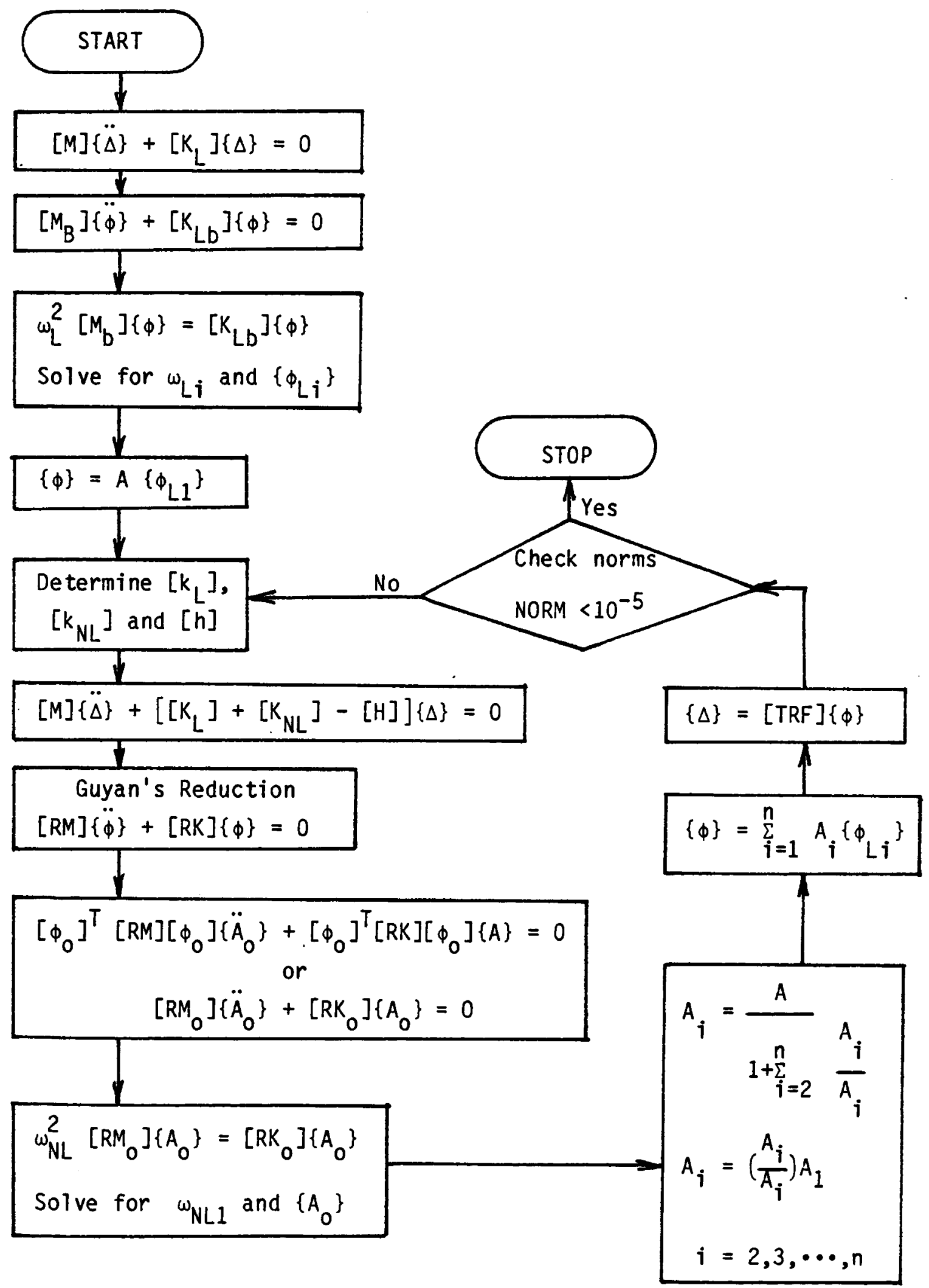

Fig. 3 Computer Flow-Chart (Solution Procedures) 
NUMBER OF ITERATION

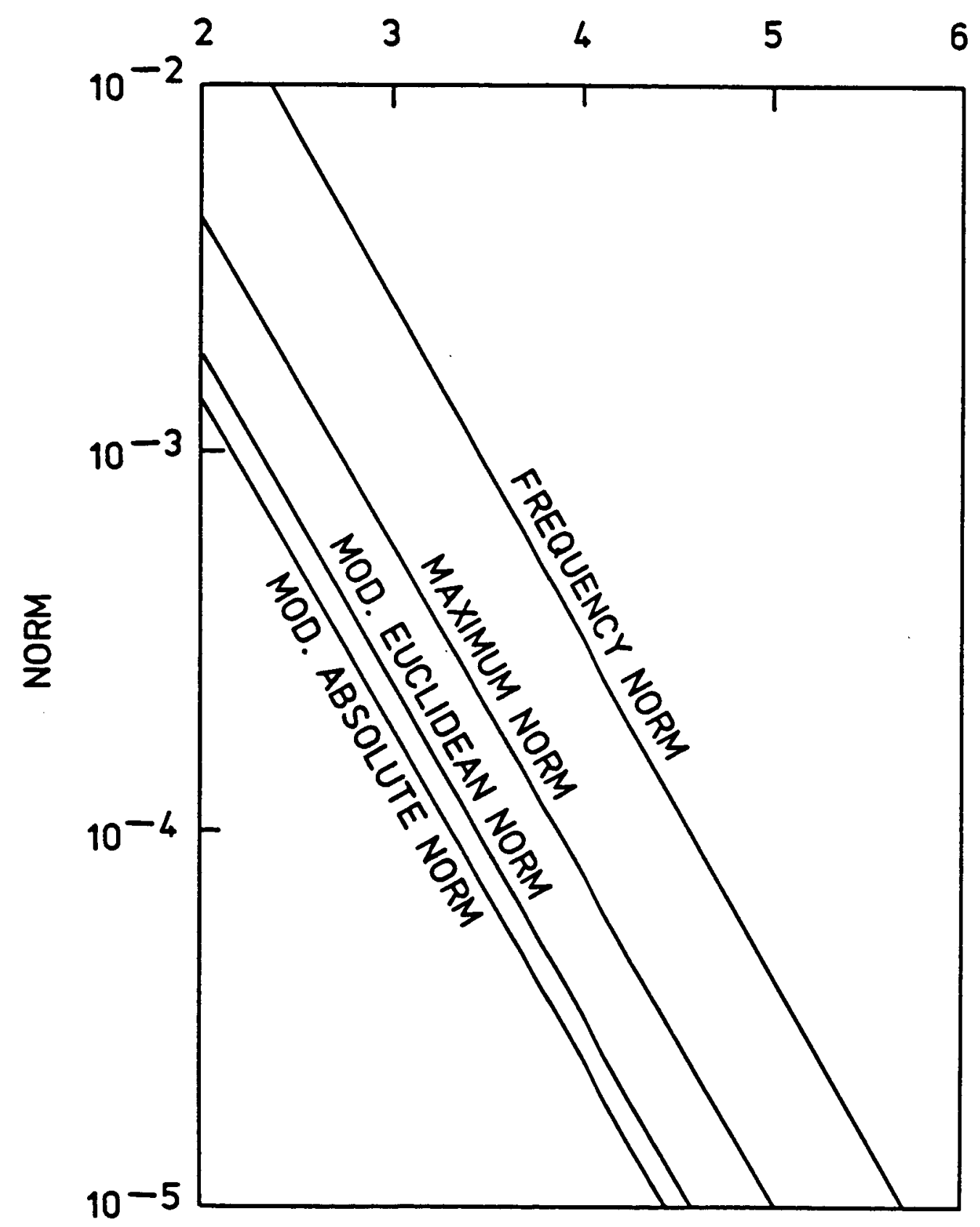

Fig. 4. Convergence characteristics of a simply supported beam W/O IDI, distributed force $F_{0}=0.001 \mathrm{~N} / \mathrm{mm}, 3$ modes $A / R=2.0$. 
frequency norm is defined $\left|\left(\Delta \omega_{\mathrm{NL}}\right)_{j} /\left(\omega_{\mathrm{NL}}\right)_{j}\right|$ where $\left(\Delta \omega_{\mathrm{NL}}\right)_{j}$ is the change in nonlinear frequency during the $j$-th iterative cycle. Fig. 4 shows a typical plot of these four norms versus number of iterations for a three-mode simply supported beam $(L / R=1010)$ without inplane displacement and inertia (IDI) subjected to a uniformly distributed harmonic force $F_{0}=0.001 \mathrm{~N} / \mathrm{mm}$ at $A / R=2.0$. Fig. 5 shows a plot of these four norms versus number of $i$ terations for a three-mode clamped beam $(L / R=1010)$ with inplane displacement and inertia (IDI) when both ends are immovable $(u=0$ at $x=0$ and $L)$ and the beam is subjected to a uniformly distributed harmonic force $F_{0}=0.002 \quad \mathrm{~N} / \mathrm{mm}$ at $A / R=4.0$. For all of the following results presented in this study, convergence is considered to be achieved whenever any one of the norms reaches a value of $10^{-5}$. 


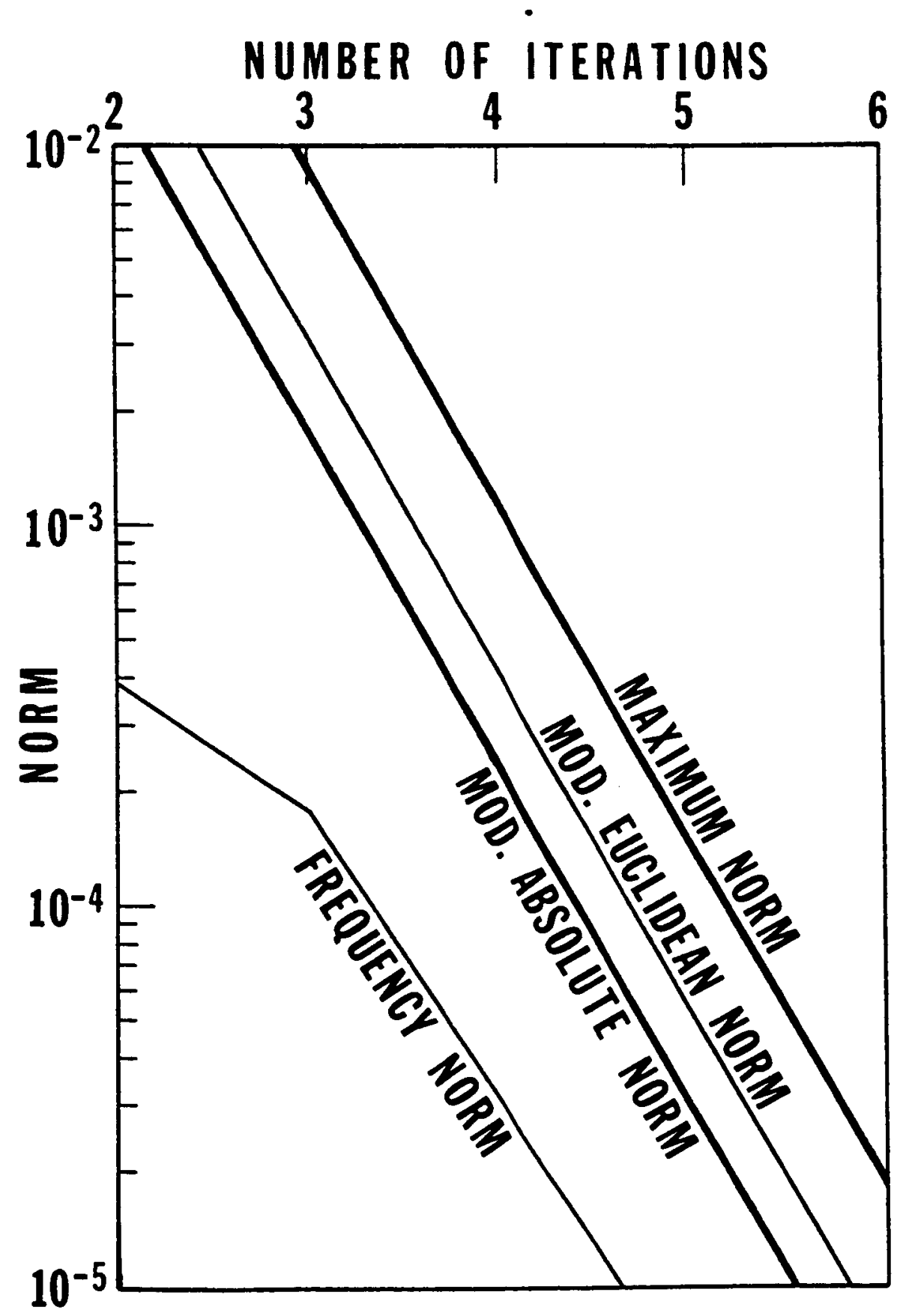

Fig. 5. Convergence characteristics of a clamped beam W/IDI immovable, distributed force $F_{0}=0.002 \mathrm{~N} / \mathrm{mm}, 3$ modes, $A / R=4.0$. 


\section{Chapter 5}

\section{RESULTS AND DISCUSSIONS}

The fundamental frequency ratio $\left(\omega=\omega_{\mathrm{NLI}} / \omega_{L 1}\right)$ of multiple-mode nonlinear free and forced vibrations at various amplitudes for simply supported and clamped beams are reported in this chapter. Both immovable and movable inplane edges conditions are considered. Finite element results with and without inplane displacement and inertia (IDI) are given. The meaning of "without inplane dispalcement and inertia" is to neglect $\{\zeta\}$, Eq. (4.3), completely from the formulation. The harmonic balance solution ${ }^{17}$, Runge-Kutta solution and experimental result $t^{18}$ are also given for comparison with the finite element results. Because of symmetry, only a half of beam divided into twenty elements of equal length is considered herein.

\subsection{Boundary Conditions and Material Properties}

The transverse deflection boundary condition for simply supported beam is defined by letting the deflection (w) equal to zero at that location. For clamped supported beam, the transverse deflection boundary conditions are the deflection (w) and its associated slope $(w, x)$ equaled to zero at that location. The inplane boundary conditions are divided into two catagories; namely, immovable and movable inplane edge. The definition of immovable inplane edge is defined as the inplane displacement $(u)$ at the boundary equaled to 
zero. For the movable inplane edge, the inplane displacement $(u)$ is set free at the boundary.

All the results presented here are based on the following material properties:

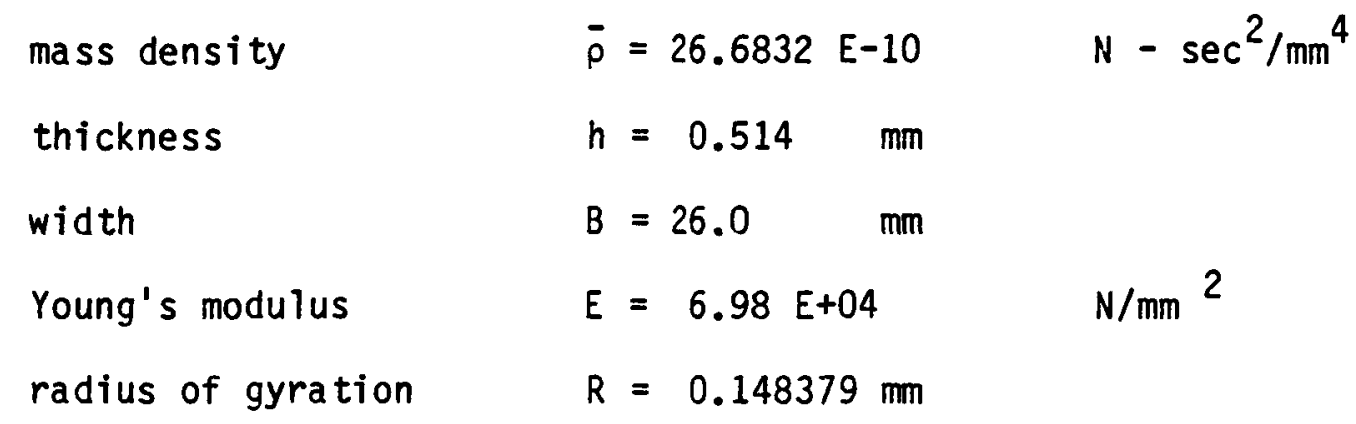

For nonlinear vibration, the effect of slenderness ratio (L/R) has some influence in the solutions. In this report, there are many slenderness ratios in use as shown in Table 1 . These slenderness ratios are calculated by changing the beam length and keeping the crosssectional area constant. Most of the results reported herein, is based on the $150 \mathrm{~mm}$. beam length $(L / R=1010)$ otherwise specified. This 150 mm. Tong beam $(L / R=1010)$ is the same dimension as the beam which Yamaki et al. 18 performed the experiment.

\subsection{Improved Nonlinear Free Vibration}

The fundamental frequency ratios $\left(\omega_{N L 1} / \omega_{L 1}\right)$ of free vibration at various amplitudes (A/R) without inplane displacement and inertia (IDI) for clamped and simply supported beams $(L / R=1010)$ are shown in Table 2 for the cases of single, two and three-mode method, respectively. The amplitude ratio for these beams are also provided in Table 3 . Table 2 shows that the more numbers of modes are used in the analysis, the less the frequency ratios will be, e.g., at $A / R=5.0$, the three-mode 
Table 1 Relations Between Slenderness Ratio $(L / R)$ and Beam Length

\begin{tabular}{lr}
\hline $\begin{array}{l}\text { Slenderness } \\
\text { Ratio } \\
L / R\end{array}$ & $\begin{array}{l}\text { Beam } \\
\text { Length } \\
\text { (mm.) }\end{array}$ \\
\hline 1010 & \\
100 & 150.000 \\
50 & 14.840 \\
20 & 7.420 \\
& 2.968 \\
\hline
\end{tabular}


Table 2 Frequency Ratios for Nonlinear Free Vibration of Clamped and Simply Supported Beams $(L / R=1010)$ without Inplane Displacement and Inertia (IDI)

\begin{tabular}{|c|c|c|c|c|}
\hline \multirow{3}{*}{$A / R$} & \multicolumn{3}{|c|}{ Frequency Ratio, $\omega_{N L 1} / \omega_{L 1}$} & \multirow[b]{2}{*}{3 modes } \\
\hline & \multicolumn{2}{|c|}{1 mode } & \multirow{2}{*}{$\begin{array}{l}2 \text { modes } \\
\text { Finite } \\
\text { Element }\end{array}$} & \\
\hline & $\begin{array}{l}\text { Finite } \\
\text { Element }\end{array}$ & $\begin{array}{l}\text { Elliptic } \\
\text { Solution }\end{array}$ & & $\begin{array}{l}\text { Finite } \\
\text { Element }\end{array}$ \\
\hline \multicolumn{5}{|c|}{ Clamped Beam } \\
\hline 1.0 & 1.0218 & 1.0222 & $1.0218(2)^{a}$ & $1.0217(3)$ \\
\hline 2.0 & 1.0845 & 1.0857 & 1.0844 (3) & $1.0831 \quad(4)$ \\
\hline 3.0 & 1.1817 & 1.1831 & $1.1814 \quad(5)$ & $1.1757(4)$ \\
\hline 4.0 & 1.3056 & 1.3064 & $1.3051(6)$ & $1.2900(6)$ \\
\hline 5.0 & 1.4495 & 1.4488 & $1.4490(8)$ & $1.4188(9)$ \\
\hline \multicolumn{5}{|c|}{ Simply Supported Beam } \\
\hline 1.0 & 1.0897 & 1.0892 & $1.0888 \quad(3)$ & $1.0888(3)$ \\
\hline 2.0 & 1.3229 & 1.3178 & $1.3120(5)$ & $1.3119(5)$ \\
\hline 3.0 & 1.6394 & 1.6257 & $1.6030(7)$ & $1.6022(7)$ \\
\hline 4.0 & 2.0000 & 1.9760 & $1.9248(11)$ & $1.9218(11)$ \\
\hline 5.0 & 2.3848 & 2.3501 & $2.2624(17)$ & $2.2549(18)$ \\
\hline
\end{tabular}

a. Number in brackets denotes the number of $i$ terations to get a converged solution $10^{-5}$ 
Table 3 Amplitude Ratios for Nonlinear Free Vibration of Clamped and Simply Supported Beams $(L / R=1010)$ without Inplane Displacement and Inertia (IDI)

\begin{tabular}{|c|c|c|c|}
\hline \multirow{3}{*}{$A / R$} & \multicolumn{3}{|c|}{ Amplitude Ratio } \\
\hline & \multirow{2}{*}{$\frac{2 \text { modes }}{A_{1} / A_{2}}$} & \multicolumn{2}{|c|}{3 modes } \\
\hline & & $A_{1} / A_{2}$ & $A_{1} / A_{3}$ \\
\hline \multicolumn{4}{|c|}{ Clamped Beam } \\
\hline 1.0 & -1054 & -1056 & 2164 \\
\hline 2.0 & -280 & -282 & 559 \\
\hline 3.0 & -137 & -139 & 261 \\
\hline 4.0 & -87 & -89 & 157 \\
\hline 5.0 & -64 & -66 & 109 \\
\hline \multicolumn{4}{|c|}{ Simply Supported Beam } \\
\hline 1.0 & 446 & 446 & $\star$ \\
\hline 2.0 & 125 & 125 & 7652 \\
\hline 3.0 & 66 & 66 & 1972 \\
\hline 4.0 & 45 & 44 & 848 \\
\hline 5.0 & 35 & 34 & 480 \\
\hline
\end{tabular}


solution yields smaller frequency ratios than the two-mode solution. Table 3 shows the influence of the amplitudes of the higher modes, especially the amplitude of second mode. Table 4 shows the comparison of a two-mode response between the finite element method and the RungeKutta method for clamped and simply supported beams $(L / R=1010)$ without inplane displacement and inertia (IDI). This clearly demonstrates the remarkable agreement between finite element and Runge-Kutta solutions. These results are also shown in Figures 6 and 7 for the clamped and simply supported cases, respectively.

The clamped and simply supported free vibration results $(L / R=1010)$ with inplane displacement and inertia (IDI) for both ends restrained from longitudinal movement (immovable case) are shown in Table 5. The amplitude ratios for this clamped beam are also shown in Table 6. The frequency-amplitude relationships for three-mode responses of these clamped and simply supported beams are also shown in Figure 8. This figure clearly shows that the simply supported beam yields the higher nonlinearity than the clamped beam.

The responses for both ends free to move longitudinally (movable case) are shown in Tables 7 and 8 . Table 7 shows the frequencyamplitude relations for three-mode solution of clamped and simply supported beams with inplane deformation and inertia for the slenderness ratio of 100,50 and 20 . The result for the clamped case is also shown in Figure 9. From this figure, the high slenderness ratio beam $(L / R=100)$ yields almost none of nonlinearity. Conversely, the less slenderness ratio case $(L / R=20)$ leads to a situation that eventually exhibits slightly softening type nonlinearity. The softened type exists when the nonlinear frequency is less the linear frequency $(\omega<1.0)$. 
Table 4 Comparison Between Runge-Kutta Method and Finite Element Method for Two-Mode Nonlinear Free Vibration of Clamped and Simply Supported Beams $(L / R=1010)$ without Inplane Displacement and Inertia (IDI).

\begin{tabular}{|c|c|c|c|}
\hline \multirow{2}{*}{$A / R$} & \multicolumn{2}{|c|}{ Frequency Ratio, $\omega_{\mathrm{NLI}} / \omega_{L I}$} & \multirow{2}{*}{$\%$ Difference ${ }^{\dagger}$} \\
\hline & Finite Element & Runge-Kutta & \\
\hline \multicolumn{4}{|c|}{ Clamped Beam } \\
\hline 1.0 & 1.0218 & 1.0222 & 0.04 \\
\hline 2.0 & 1.0845 & 1.0852 & 0.07 \\
\hline 3.0 & 1.1817 & 1.1810 & 0.03 \\
\hline 4.0 & 1.3056 & 1.3009 & 0.32 \\
\hline 5.0 & 1.4495 & 1.4373 & 0.81 \\
\hline \multicolumn{4}{|c|}{ Simply Supported Beam } \\
\hline 1.0 & 1.0888 & 1.0888 & 0.00 \\
\hline 2.0 & 1.3120 & 1.3135 & 0.11 \\
\hline 3.0 & 1.6030 & 1.6115 & 0.53 \\
\hline 4.0 & 1.9248 & 1.9467 & 1.13 \\
\hline 5.0 & 2.2624 & 2.3023 & 1.73 \\
\hline
\end{tabular}




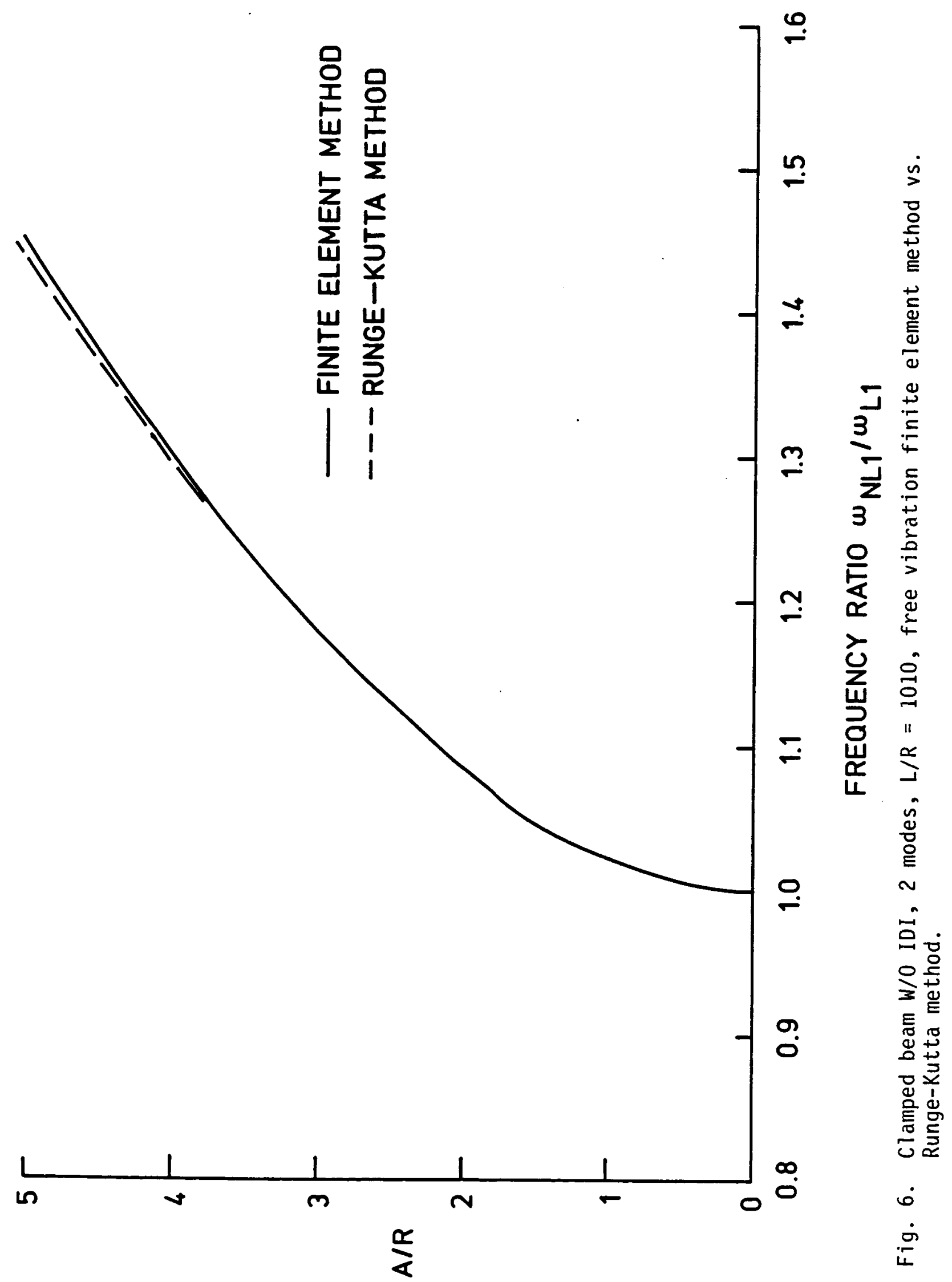




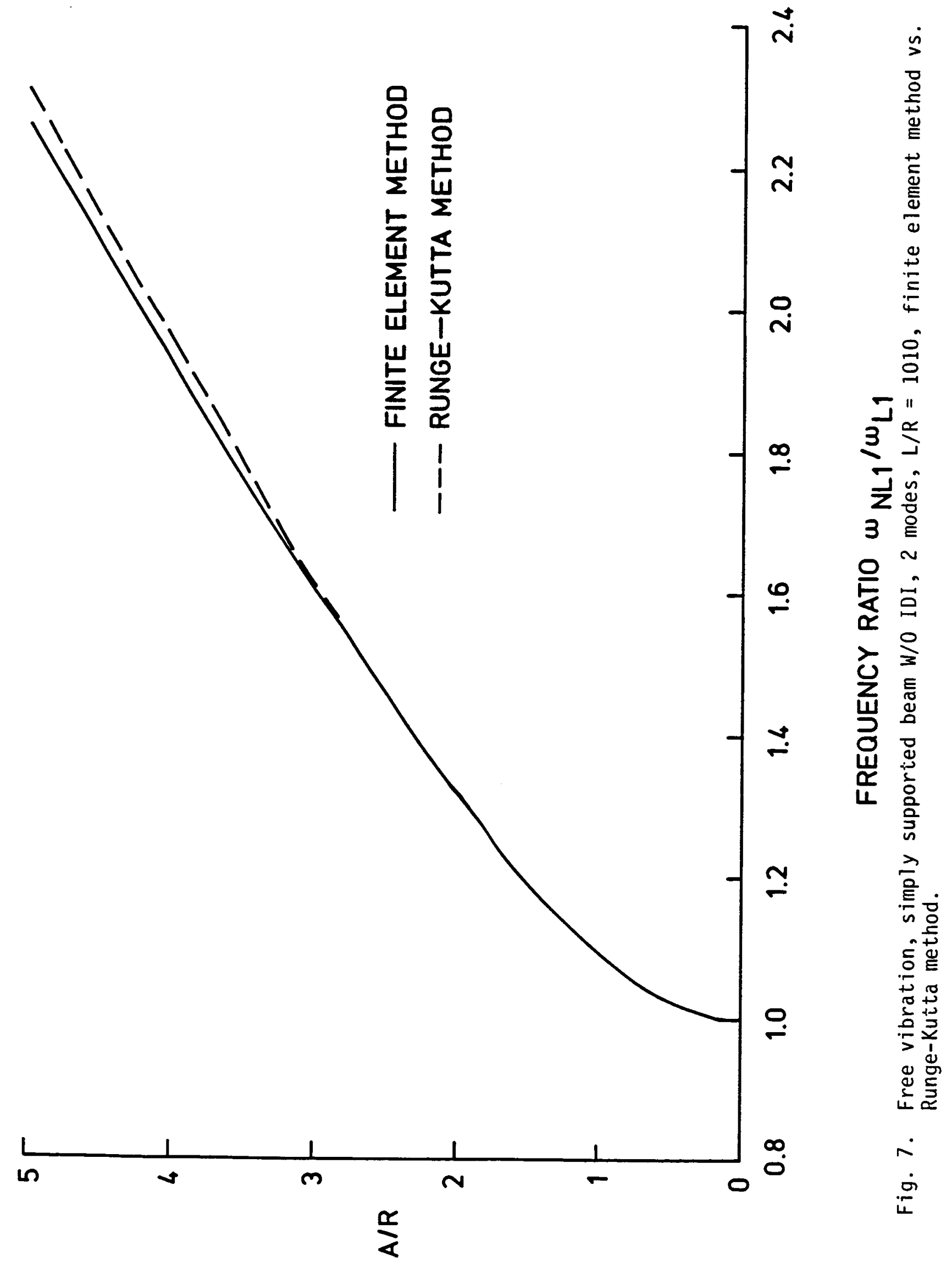


Table 5 Frequency Ratios for Nonlinear Free Vibration of Clamped and Simply Supported Immovable Beams $(L / R=1010)$ with Inplane Displacement and Inertia (IDI)

\begin{tabular}{|c|c|c|c|c|}
\hline \multirow{3}{*}{$A / R$} & \multicolumn{4}{|c|}{ Frequency Ratio, $\omega_{N L 1} / \omega_{L 1}$} \\
\hline & \multicolumn{2}{|c|}{1 mode } & \multirow{2}{*}{$\begin{array}{l}2 \text { modes } \\
\text { Finite } \\
\text { Element }\end{array}$} & \multirow{2}{*}{$\begin{array}{l}3 \text { modes } \\
\text { Finite } \\
\text { Element }\end{array}$} \\
\hline & $\begin{array}{l}\text { Finite } \\
\text { Element }\end{array}$ & $\begin{array}{l}\text { Rayleigh } \\
\text { Ritz }\end{array}$ & & \\
\hline \multicolumn{5}{|c|}{ Clamped Beam } \\
\hline 1.0 & 1.0149 & - & $1.0149(2)^{a}$ & $1.0149(2)$ \\
\hline 2.0 & 1.0582 & - & $1.0581(3)$ & 1.0581 (3) \\
\hline 3.0 & 1.1268 & - & $1.1264(4)$ & $1.1259(4)$ \\
\hline 4.0 & 1.2164 & - & $1.2151(5)$ & $1.2140(2)$ \\
\hline 5.0 & 1.3226 & - & $1.3202(6)$ & $1.3176(6)$ \\
\hline \multicolumn{5}{|c|}{ Simply Supported Beam } \\
\hline 1.0 & 1.0607 & $1.0607^{b}$ & 1.0607 (2) & $1.0607(2)$ \\
\hline 2.0 & 1.2247 & 1.2246 & $1.2247(2)$ & $1.2247(2)$ \\
\hline 3.0 & 1.4577 & 1.4573 & $1.4577(2)$ & 1.4577 (2) \\
\hline 4.0 & 1.7320 & 1.7309 & $1.7320(2)$ & $1.7320(2)$ \\
\hline 5.0 & 2.0310 & 2.0289 & $2.0310(2)$ & $2.0310(2)$ \\
\hline
\end{tabular}

a. Number in brackets denotes the number of $i$ terations to get a converged solution $10^{-5}$

b. $L / R=100$ 
Table 6 Amplitude Ratios for Nonlinear Free Vibration of Clamped Immovable Beams $(L / R=1010)$ with Inplane Displacement and Inertia (IDI)

\begin{tabular}{|c|c|c|c|}
\hline \multirow{3}{*}{$A / R$} & \multicolumn{3}{|c|}{ Amplitude Ratio } \\
\hline & \multirow{2}{*}{$\frac{2 \text { modes }}{A_{1} / A_{2}}$} & \multicolumn{2}{|c|}{3 modes } \\
\hline & & $A_{1} / A_{2}$ & $A_{1} / A_{3}$ \\
\hline 1.0 & -1354 & -1354 & * \\
\hline 2.0 & -346 & -346 & 2690 \\
\hline 3.0 & -159 & -159 & 1202 \\
\hline 4.0 & -94 & -95 & 678 \\
\hline 5.0 & -64 & -64 & 442 \\
\hline
\end{tabular}




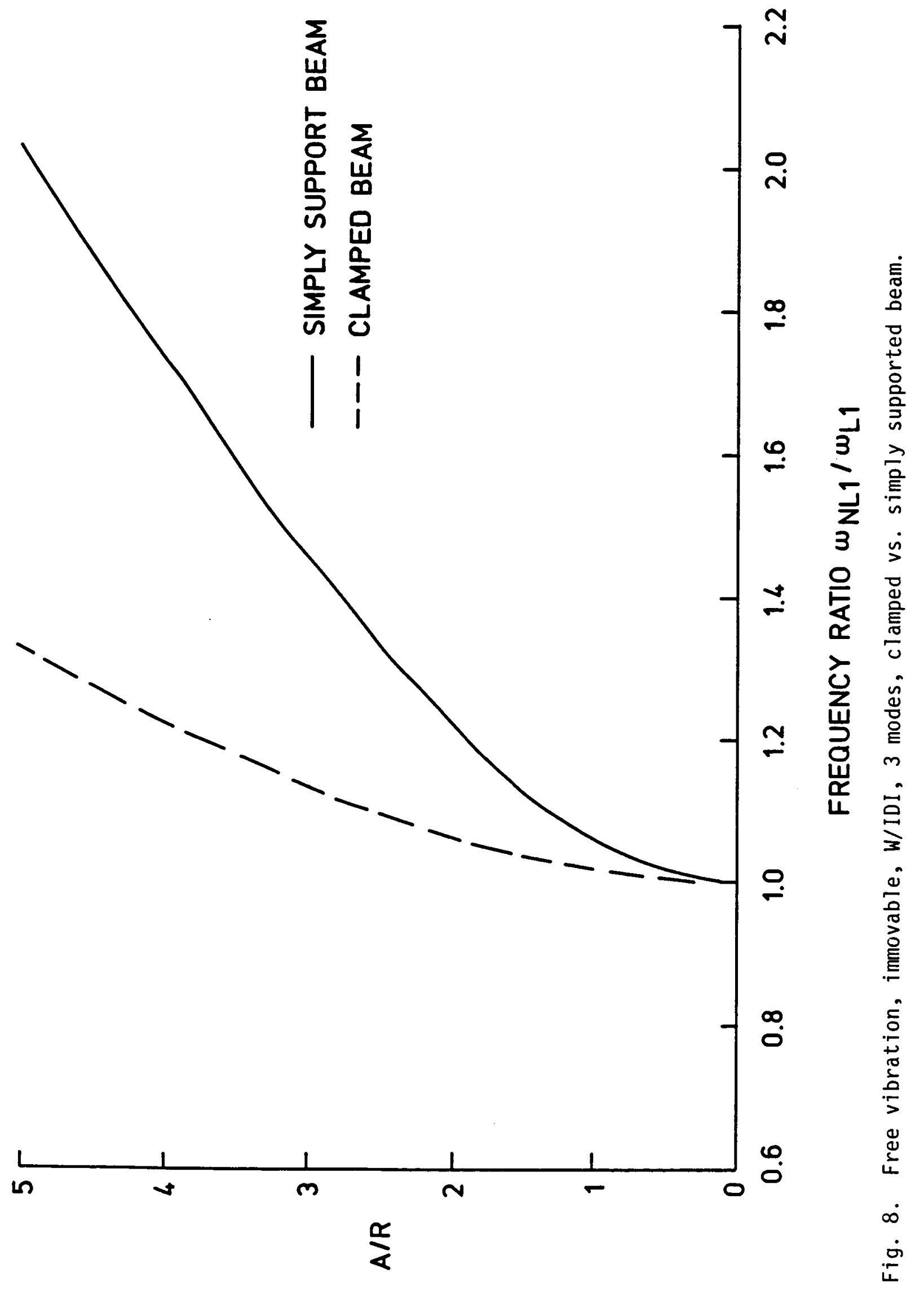


Table 7 Frequency Ratios $\left(\omega_{N L 1} / \omega_{L 1}\right)$ for Three-Mode Nonlinear Free Vibration of Clamped and Simply Supported Movable Beams with Inplane Displacement and Inertia (IDI) for Different Slenderness Ratio (L/R)

\begin{tabular}{lccc}
\hline \multirow{5}{*}{$A / R$} & \multicolumn{5}{c}{ Sienderness Ratio, L/R } \\
\cline { 2 - 6 } & \multicolumn{5}{c}{50} \\
\hline 100 & Clamped Beam \\
2.0 & $.9999(2)^{a}$ & $.9997(2)$ & $.9983(2)$ \\
3.0 & $.9997(2)$ & $.9989(2)$ & $.9933(2)$ \\
4.0 & $.9994(2)$ & $.9976(2)$ & $.9850(3)$ \\
5.0 & $.9989(2)$ & $.9957(2)$ & $.9737(3)$ \\
& $.9983(2)$ & $.9933(2)$ & $.9596(3)$ \\
\hline 1.0 & & & Simply Supported Beam \\
2.0 & $1.0000(2)$ & $.9999(2)$ & $.9993(2)$ \\
3.0 & $.9999(2)$ & $.9996(2)$ & $.9973(2)$ \\
4.0 & $.9998(2)$ & $.9990(2)$ & $.9938(2)$ \\
5.0 & $.9996(2)$ & $.9982(2)$ & $.9891(2)$ \\
& $.9993(2)$ & $.9973(2)$ & $.9832(2)$ \\
\hline
\end{tabular}

a. Number in brackets denotes the number of iterations to get a converged solution $10^{-5}$. 
Table 8 Amplitude Ratios for Three-Mode Nonlinear Free Vibration of Clamped and Simply Supported Moveable Beams $(L / R=20)$ with Inplane Displacement and Inertia (IDI)

\begin{tabular}{|c|c|c|}
\hline \multirow{2}{*}{$A / R$} & \multicolumn{2}{|c|}{ Amplitude Ratio } \\
\hline & $A_{1} / A_{2}$ & $A_{1} / A_{3}$ \\
\hline \multicolumn{3}{|c|}{ Clamped beam } \\
\hline 1.0 & 6410 & * \\
\hline 2.0 & 1613 & * \\
\hline 3.0 & 724 & -8914 \\
\hline 4.0 & 414 & -5152 \\
\hline 5.0 & 270 & -3413 \\
\hline \multicolumn{3}{|c|}{ Simply Supported Beam } \\
\hline 1.0 & * & * \\
\hline 2.0 & * & * \\
\hline 3.0 & 5178 & * \\
\hline 4.0 & 2936 & $\star$ \\
\hline 5.0 & 1898 & * \\
\hline
\end{tabular}



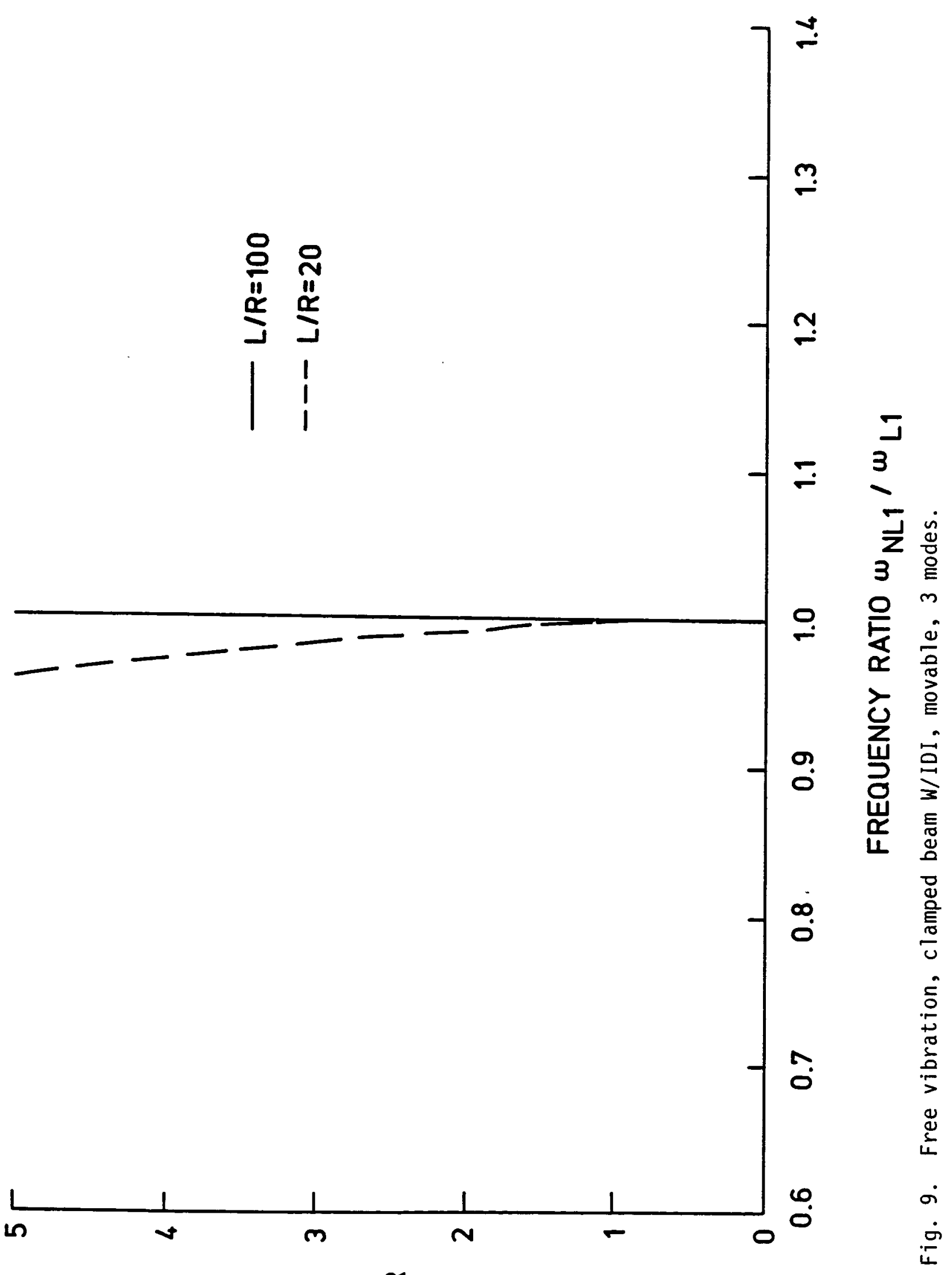

$\frac{1}{\alpha}$ 
Atluri ${ }^{8}$ also obtained the similar softening type in his investigation. For the simply supported case as shown in Table 7, it exhibits less influence of softening type than the clamped case. Table 8 shows the amplitude ratios for three-mode solution of clamped and simply supported movable beams $(L / R=20)$ with $I D I$. The comparison of the amplitude ratio between the movable clamped case (Table 8 ) and the immovable clamped case (Table 6) shows that the higher modes have more influence on the immovable case than the movable case.

\subsection{Nonlinear Response to Distributed Harmonic Force}

The responses of clamped and simply supported beams $(L / R=1010)$ without IDI are shown in Tables 9 and 10. Table 9 shows the frequency ratios for the cases of single, two and three-mode approaches. It should be noted that as the amplitude is increased, the more iteration is needed. The amplitude ratios for these beams is shown in Table 10 . The frequency-amplitude relations for these clamped and simply supported beams with various force intensity $\left(F_{0}\right)$ are also plotted in Figures 10 and 11 for the three-mode solution, respectively.

The responses of clamped and simply supported immovable beams $(L / R=1010)$ with IDI are shown in Tables 11 and 12 . Table 11 shows the frequency ratios for the cases of single, two and three-mode approaches. It also shows that the nigher modes are more important for the clamped beam than the simply supported beam. This can be observed by looking at one of the amplitude, eg. $A / R=+5.0$, the frequency ratio for the clamped beam is changed for different numbers of modes used in the formulation, but the frequency ratio for the simply supported beam 
Table 9 Frequency Ratios for Nonlinear Forced Vibration of Clamped and Simply Supported Beams $(L / R=1010)$ wi thout Inplane Displacement and Inertia (IDI) under Uniform Harmonic Distributed Force

\begin{tabular}{|c|c|c|c|}
\hline \multirow{2}{*}{$A / R$} & \multicolumn{3}{|c|}{ Frequency Ratio, $\omega_{N L 1} / \omega_{L 1}$} \\
\hline & 1 mode & 2 modes & 3 modes \\
\hline \multicolumn{4}{|c|}{ Clamped Beam: $F_{0}=0.002 \mathrm{~N} / \mathrm{mm}$} \\
\hline-1.0 & $\begin{array}{r}.4101 \\
1.3856\end{array}$ & $\begin{array}{r}.4105(3)^{a} \\
1.3855(3)\end{array}$ & $\begin{array}{r}.4097(3) \\
1.3856(2)\end{array}$ \\
\hline - 2.0 & $\begin{array}{r}.8592 \\
1.2705\end{array}$ & $\begin{array}{r}.8595(4) \\
1.2701(3)\end{array}$ & $\begin{array}{r}.8573(3) \\
1.2694(4)\end{array}$ \\
\hline \pm 3.0 & $\begin{array}{l}1.0509 \\
1.2994\end{array}$ & $\begin{array}{ll}1.0511 & (5) \\
1.2987 & (4)\end{array}$ & $\begin{array}{l}1.0440(5) \\
1.2940(4)\end{array}$ \\
\hline \pm 4.0 & $\begin{array}{l}1.2189 \\
1.3869\end{array}$ & $\begin{array}{l}1.2189(6) \\
1.3860(6)\end{array}$ & $\begin{array}{l}1.2019(7) \\
1.3725(6)\end{array}$ \\
\hline \pm 5.0 & $\begin{array}{l}1.3877 \\
1.5087\end{array}$ & $\begin{array}{l}1.3878(8) \\
1.5078(8)\end{array}$ & $\begin{array}{l}1.3554(9) \\
1.4794(8)\end{array}$ \\
\hline \multicolumn{4}{|c|}{ Simply Supported Beam: $F_{0}=0.001 \mathrm{~N} / \mathrm{mm}$} \\
\hline-1.0 & 1.8328 & $1.8331 \quad(3)$ & 1.8331 (3) \\
\hline \pm 2.0 & $\begin{array}{r}.8150 \\
1.6840\end{array}$ & $\begin{array}{r}.7937(5) \\
1.6771(5)\end{array}$ & $\begin{array}{r}.7934 \text { (5) } \\
1.6771 \text { (5) }\end{array}$ \\
\hline \pm 3.0 & $\begin{array}{l}1.4013 \\
1.8470\end{array}$ & $\begin{array}{l}1.3560(7) \\
1.8168(7)\end{array}$ & $\begin{array}{l}1.3549(7) \\
1.8162(7)\end{array}$ \\
\hline \pm 4.0 & $\begin{array}{l}1.8593 \\
2.1314\end{array}$ & $\begin{array}{l}1.7760(11) \\
2.0629(11)\end{array}$ & $\begin{array}{l}1.7725(11) \\
2.0603(11)\end{array}$ \\
\hline \pm 5.0 & $\begin{array}{l}2.2920 \\
2.4742\end{array}$ & $\begin{array}{l}2.1625(17) \\
2.3581(17)\end{array}$ & $\begin{array}{ll}2.1543 & (18) \\
2.3511 & (18)\end{array}$ \\
\hline
\end{tabular}

a. Number in brackets denotes the number of iterations to get a converged solution $10^{-5}$ 
Table 10 Amplitude Ratios for Nonlinear Forced Vibration of Clamped and Simply Supported Beams $(L / R=1010)$ wi thout Inplane Displacement and Inertia (IDI) under Uniform Harmonic Distributed Force

\begin{tabular}{|c|c|c|c|}
\hline \multirow{3}{*}{$A / R$} & \multicolumn{3}{|c|}{ Amplitude Ratio } \\
\hline & \multirow{2}{*}{$\frac{2 \text { modes }}{A_{1} / A_{2}}$} & \multicolumn{2}{|c|}{3 modes } \\
\hline & & $A_{1} / A_{2}$ & $A_{1} / A_{3}$ \\
\hline \multicolumn{4}{|c|}{ Clamped Beam: $F_{0}=0.002 \mathrm{~N} / \mathrm{mm}$} \\
\hline \pm 1.0 & -1054 & -1056 & 2164 \\
\hline \pm 2.0 & -280 & -282 & 559 \\
\hline \pm 3.0 & -137 & -139 & 261 \\
\hline \pm 4.0 & -87 & -89 & 157 \\
\hline \pm 5.0 & -64 & -66 & 109 \\
\hline \multicolumn{4}{|c|}{ Simply Supported Beam: $F_{0}=0.001 \mathrm{~N} / \mathrm{mm}$} \\
\hline-1.0 & 446 & 446 & * \\
\hline \pm 2.0 & 125 & 125 & 7652 \\
\hline \pm 3.0 & 66 & 66 & 1972 \\
\hline \pm 4.0 & 45 & 44 & 848 \\
\hline \pm 5.0 & 35 & 34 & 480 \\
\hline
\end{tabular}




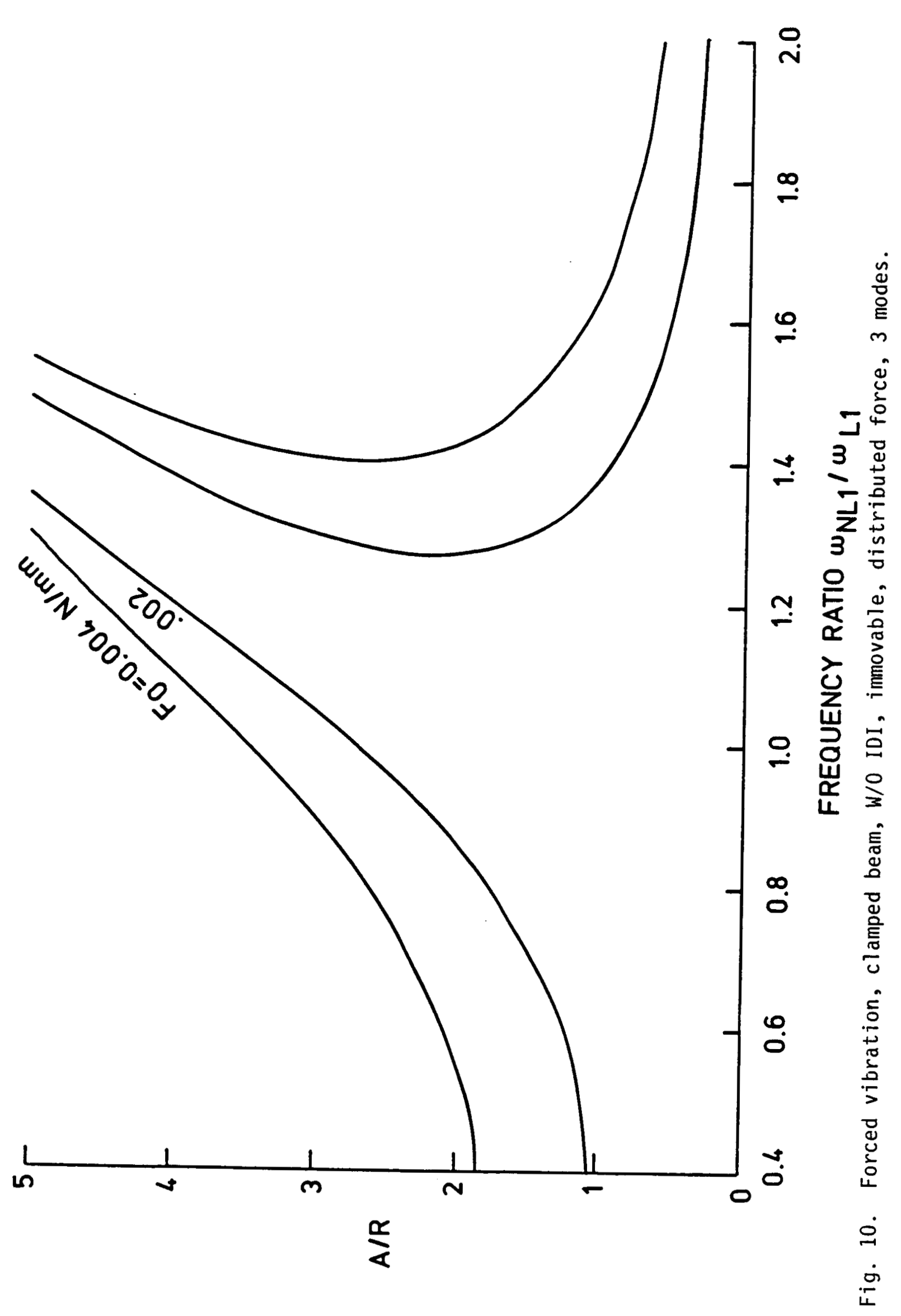




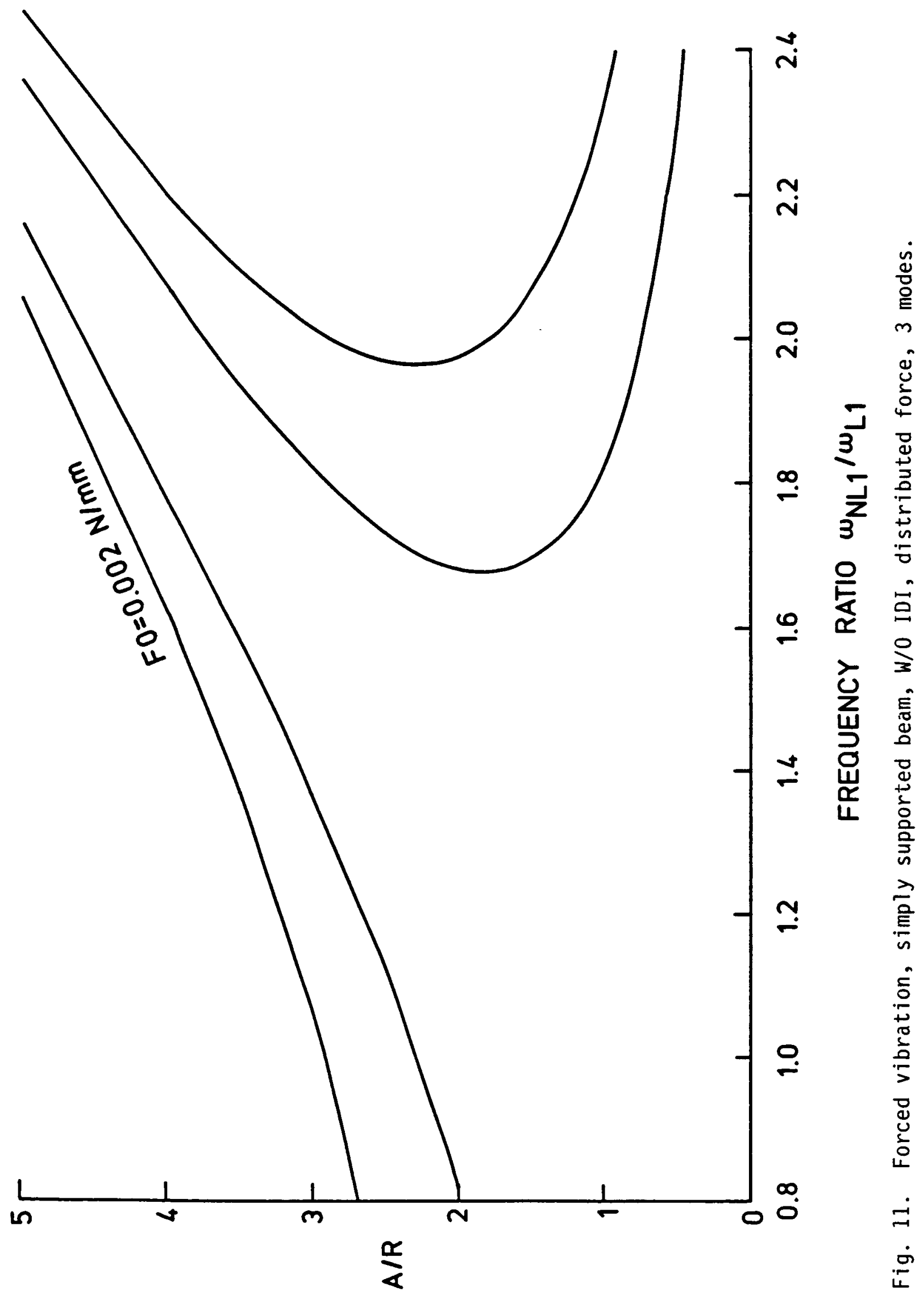


Table 11 Frequency Ratios for Nonlinear Forced Vibration of Clamped and Simply Supported Immovable Beams $(L / R=1010)$ with Inplane Displacement and Inertia (IDI) under Uniform Harmonic Distributed Force

\begin{tabular}{|c|c|c|c|}
\hline \multirow{2}{*}{$A / R$} & \multicolumn{3}{|c|}{ Frequency Ratio, $\omega_{N L 1} / \omega_{L 1}$} \\
\hline & 1 mode & 2 modes & 3 modes \\
\hline \multicolumn{4}{|c|}{ Clamped Beam: $F_{0}=0.002 \mathrm{~N} / \mathrm{mm}$. } \\
\hline \pm 1.0 & $\begin{array}{r}.3925 \\
1.3805\end{array}$ & $\begin{array}{l}.3929(3)^{a} \\
1.3804(3)\end{array}$ & $\begin{array}{r}.3928(3) \\
1.3804(3)\end{array}$ \\
\hline \pm 2.0 & $\begin{array}{r}.8258 \\
1.2481\end{array}$ & $\begin{array}{r}.8260(4) \\
1.2478 \quad(3)\end{array}$ & $\begin{array}{r}.8258(4) \\
1.2478(3)\end{array}$ \\
\hline \pm 3.0 & $\begin{array}{r}.9888 \\
1.2497\end{array}$ & $\begin{array}{r}.9888(4) \\
1.2489(3)\end{array}$ & $\begin{array}{r}.9881 \\
1.2486\end{array}$ \\
\hline \pm 4.0 & $\begin{array}{l}1.1227 \\
1.3033\end{array}$ & $\begin{array}{ll}1.1220 & (5) \\
1.3017 & (4)\end{array}$ & $\begin{array}{ll}1.1205 & (5) \\
1.3007 & (4)\end{array}$ \\
\hline \pm 5.0 & $\begin{array}{l}1.2546 \\
1.3872\end{array}$ & $\begin{array}{ll}1.2527 & (6) \\
1.3845 & (6)\end{array}$ & $\begin{array}{ll}1.2497 & (6) \\
1.3821 & (6)\end{array}$ \\
\hline \multicolumn{4}{|c|}{ Simply Supported Beam $F_{0}=0.001 \mathrm{~N} / \mathrm{mm}$} \\
\hline-1.0 & 1.8156 & 1.8156 (2) & 1.8156 (2) \\
\hline \pm 2.0 & $\begin{array}{r}.6436 \\
1.6080\end{array}$ & $\begin{array}{rr}.6436 & (2) \\
1.6080 & (2)\end{array}$ & $\begin{array}{r}.6436(2) \\
1.6080(2)\end{array}$ \\
\hline \pm 3.0 & $\begin{array}{l}1.1837 \\
1.6879\end{array}$ & $\begin{array}{ll}1.1837 & (2) \\
1.6879 & (2)\end{array}$ & $\begin{array}{ll}1.1837 & (2) \\
1.6879 & (2)\end{array}$ \\
\hline \pm 4.0 & $\begin{array}{l}1.5675 \\
1.8823\end{array}$ & $\begin{array}{ll}1.5675 & (2) \\
1.8823 & (2)\end{array}$ & $\begin{array}{ll}1.5675 & (2) \\
1.8823 & (2)\end{array}$ \\
\hline \pm 5.0 & $\begin{array}{l}1.9211 \\
2.1352\end{array}$ & $\begin{array}{ll}1.9211 & (2) \\
2.1352 & (2)\end{array}$ & $\begin{array}{ll}1.9211 & (2) \\
2.1352 & (2)\end{array}$ \\
\hline
\end{tabular}

a. Number in brackets denotes the number of iterations to get a converged solution $10^{-5}$ 
Table 12 Amplitude Ratios for Nonlinear Forced Vibration of Clamped Immovable Beam $(L / R=1010)$ with Inplane Displacement and Inertia (IDI) under Uniform Harmonic Distributed Force; $F_{0}=0.002 \mathrm{~N} / \mathrm{mm}$.

\begin{tabular}{lccc}
\hline \multirow{2}{*}{$A / R$} & \multicolumn{4}{c}{ Ampli tude Ra tio } \\
\cline { 2 - 4 } & $\frac{2 \text { modes }}{A_{1} / A_{2}}$ & $A_{1} / A_{2}$ & 3 modes \\
\hline 1.0 & -1354 & -1354 & $A_{1} / A_{3}$ \\
\pm 2.0 & -346 & -346 & 2689 \\
\pm 3.0 & -159 & -159 & 1202 \\
\pm 4.0 & -94 & -94 & 682 \\
\pm 5.0 & -64 & -64 & 442
\end{tabular}

* Number is larger than $\left|10^{4}\right|$ 
apparently remains the same no matter how many modes are used in the formulation. Figure 12 shows the frequency-amplitude relation for the clamped immovable beam under uniform harmonic force intensity of $F_{0}=0$ (free-vibration case), 0.002 and $0.004 \mathrm{~N} / \mathrm{mm}$. It should be noted that all curves in this figure shows the hardening type nonlinearity. Figure 13 shows the comparison of harmonic balance method ${ }^{17}$, experiment ${ }^{18}$ and finite element method for a clamped immovable beam under uniform harmonic distributed force intensity $F_{0}=0.004170277 \mathrm{~N} / \mathrm{mm}$. It clearly demonstrates the remarkable agreement between the experiment and the finite element (with IDI) solution.

The responses for the movable cases are shown in Table 13 and 14. Table 13 shows the frequency ratios and amplitude ratios for three-mode clamped movable beam with IDI under uniform harmonic force. Similarly, the results of the simply supported beam are shown in Table 14. Figure 14 shows the frequency-amplitude relation for three-mode clamped movable beam of slenderness ratio $L / R=20$. All of the curves in this figure shows that the beam eventually exhibits slightly softening type nonlinearity. Figure 15 shows the comparison between the immovable case and the movable case for a three-mode clamped beam $(L / R=100)$ with IDI under the force intensity $F_{0}=20 \mathrm{~N} / \mathrm{mm}$. This clearly shows that the movable case reduces beam nonlinearity when compared to the immovable case.

\subsection{Monlinear Response to Concentrated Harmonic Force}

The application of the finite element method to simulate the case of a concentrated force is to let the length of the loaded element 


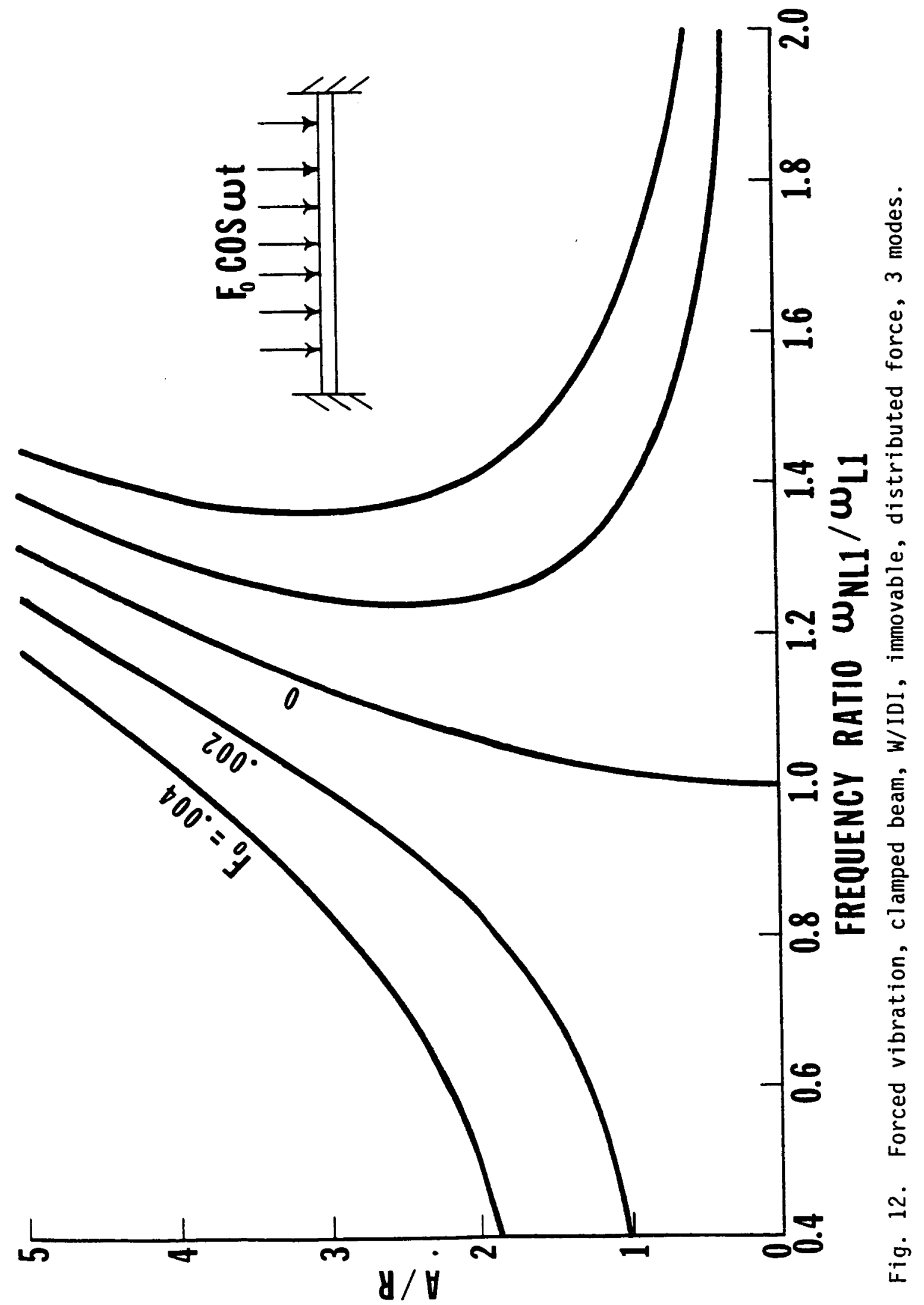




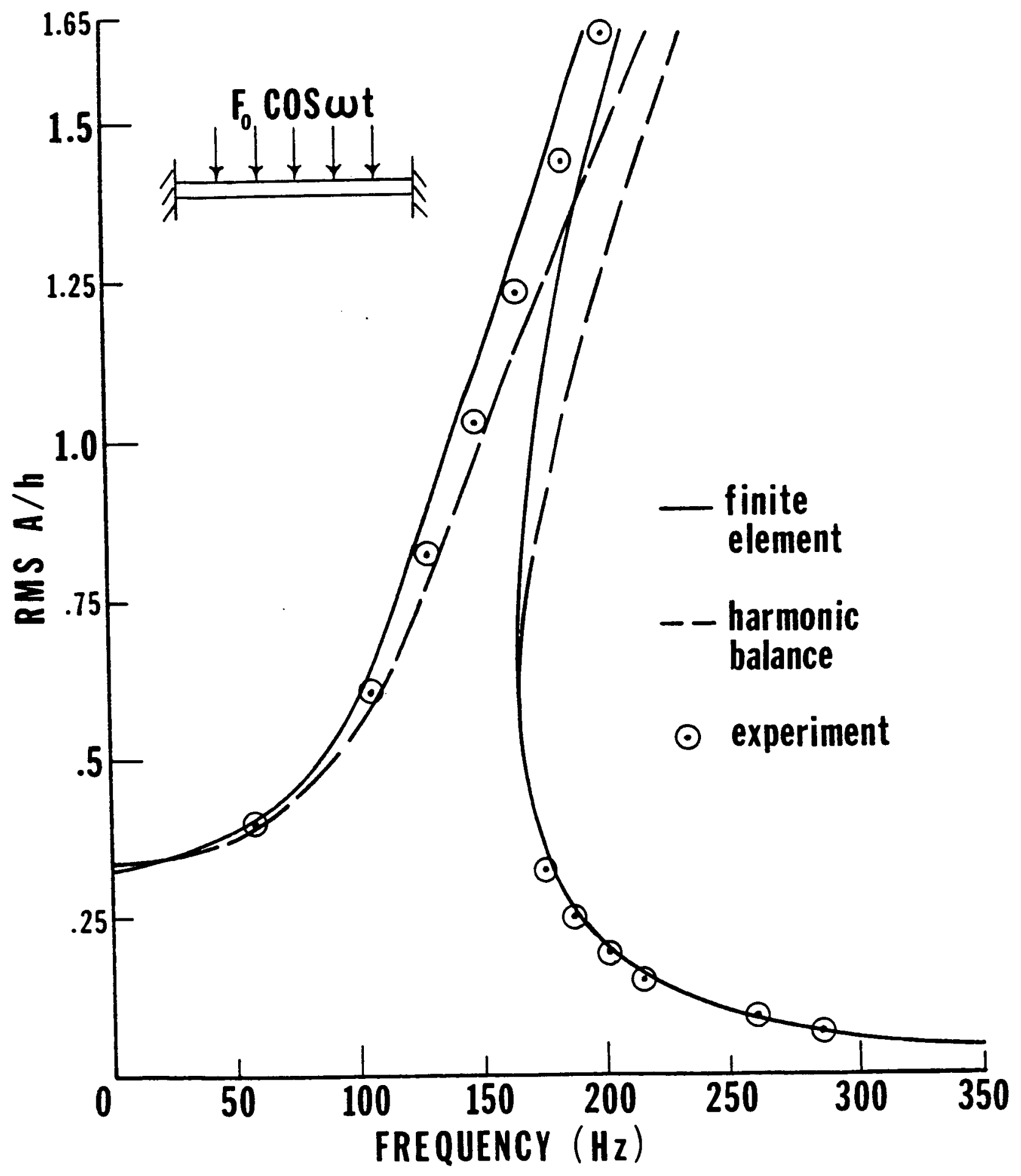

Fig. 13. Forced vibration, clamped beam, immovable distributed force $F_{0}=$ $0.004170277 \mathrm{~N} / \mathrm{mm}$ experiment vs. harmonic balance method vs. finite element method (W/IDI, 3 modes). 
Table 13 Frequency Ratios and Amplitude Ratios for Three-Mode Nonlinear Forced Vibration of Clamped Movable Beam with Inplane Displace ment and Inertia (IDI) under Uniform Harmonic Distributed Force

\begin{tabular}{|c|c|c|c|}
\hline \multirow{2}{*}{$A / R$} & \multirow{2}{*}{$\begin{array}{l}\text { Frequency } \\
\text { Ra tio, } \\
\omega_{N L 1} / \omega_{L 1}\end{array}$} & \multicolumn{2}{|c|}{ Amplitude Ratio } \\
\hline & & $A_{1} / A_{2}$ & $A_{1} / A_{3}$ \\
\hline \multicolumn{4}{|c|}{$L / R=100 ; F_{O}=20 \mathrm{~N} / \mathrm{mm}$} \\
\hline \pm 1.0 & $\begin{aligned} .4011 & (2)^{\mathrm{a}} \\
1.3560 & (2)^{2}\end{aligned}$ & $\begin{array}{l}\star \\
\star\end{array}$ & $\begin{array}{l}\star \\
\star\end{array}$ \\
\hline \pm 2.0 & $\begin{array}{rr}.7617 & (2) \\
1.1911 & (2)\end{array}$ & $\begin{array}{l}\star \\
\star\end{array}$ & $\begin{array}{l}\star \\
\star\end{array}$ \\
\hline \pm 3.0 & $\begin{array}{r}.8482(2) \\
1.1306\end{array}$ & $\begin{array}{l}\star \\
\star\end{array}$ & $\begin{array}{l}* \\
*\end{array}$ \\
\hline \pm 4.0 & $\begin{array}{r}.8880(2) \\
1.0987(2)\end{array}$ & $\begin{array}{c}\star \\
8271\end{array}$ & $\begin{array}{l}\star \\
\star\end{array}$ \\
\hline \pm 5.0 & $\begin{array}{r}.9107(2) \\
1.0788(2)\end{array}$ & $\begin{array}{l}7704 \\
5488\end{array}$ & $\begin{array}{l}\star \\
\star\end{array}$ \\
\hline & $L / R=$ & $00 \mathrm{~N} / \mathrm{mn}$ & \\
\hline \pm 1.0 & $\begin{array}{r}.8137(3) \\
1.1538 \quad(2)\end{array}$ & $\begin{array}{l}9653 \\
4797\end{array}$ & $\begin{array}{l}\star \\
\star\end{array}$ \\
\hline 2.0 & $\begin{array}{rr}.9061 & (3) \\
1.0734 & (3)\end{array}$ & $\begin{array}{l}1940 \\
1380\end{array}$ & $\begin{array}{l}\star \\
\star\end{array}$ \\
\hline-3.0 & $\begin{array}{rr}.9282 & (3) \\
1.0387 & (2)\end{array}$ & $\begin{array}{l}817 \\
651\end{array}$ & $\begin{array}{l}\star \\
-8020\end{array}$ \\
\hline \pm 4.0 & $\begin{array}{rr}.9319 & (3) \\
1.0137 & (3)\end{array}$ & $\begin{array}{l}452 \\
381\end{array}$ & $\begin{array}{l}-5620 \\
-4757\end{array}$ \\
\hline \pm 5.0 & $\begin{array}{ll}.9268 & (3) \\
.9913 & (3)\end{array}$ & $\begin{array}{l}290 \\
252\end{array}$ & $\begin{array}{l}-3655 \\
-3202\end{array}$ \\
\hline
\end{tabular}

a. Number in brackets denotes the number of iterations to get a converged solution $10^{-5}$ 
Table 14 Frequency Ratios and Amplitude Ratios for ThreeMode Nonlinear Forced Vibration of Simply Supported Movable Beam with Inplane Displacement and Inertia (IDI) under Uniform Harmonic Distributed Force

\begin{tabular}{|c|c|c|c|}
\hline \multirow{2}{*}{$A / R$} & \multirow{2}{*}{$\begin{array}{l}\text { Frequency } \\
\text { Ratio } \\
\omega_{N L 1} / \omega_{L 1}\end{array}$} & \multicolumn{2}{|c|}{ Amplitude Ratio } \\
\hline & & $\lambda_{1} / A_{2}$ & $A_{1} / A_{3}$ \\
\hline \multicolumn{4}{|c|}{$L / R=100 ; F_{O}=3 \mathrm{~N} / \mathrm{mm}$} \\
\hline \pm 1.0 & $\begin{array}{ll}.6131 & (2) \\
1.2744 & (2)\end{array}$ & * & $\begin{array}{l}\star \\
\star\end{array}$ \\
\hline \pm 2.0 & $\begin{array}{l}.8293(2) \\
1.1453(2)\end{array}$ & * & * \\
\hline \pm 3.0 & $\begin{array}{l}.8897(2) \\
1.0988(2)\end{array}$ & * & $\begin{array}{l}\star \\
\star\end{array}$ \\
\hline \pm 4.0 & $\begin{aligned} .9183 & (2) \\
1.0747 & (2)\end{aligned}$ & * & * \\
\hline \pm 5.0 & $\begin{array}{r}.9349(2) \\
1.0598(2)\end{array}$ & * & * \\
\hline \multicolumn{4}{|c|}{$L / R=20 ; F_{O}=1000 \mathrm{~N} / \mathrm{mm}$} \\
\hline \pm 1.0 & $\begin{array}{rr}.8162 & (2) \\
1.1537 & (2)\end{array}$ & $\begin{array}{l}\star \\
\star\end{array}$ & $\begin{array}{l}* \\
\star\end{array}$ \\
\hline \pm 2.0 & $\begin{array}{r}.9105 \text { (2) } \\
1.0770(2)\end{array}$ & $\stackrel{\star}{*}$ & * \\
\hline \pm 3.0 & $\begin{array}{rr}.9371 & (2) \\
1.0475 & (2)\end{array}$ & $\begin{array}{l}5825 \\
4660\end{array}$ & * \\
\hline \pm 4.0 & $\begin{array}{rr}.9471 & (3) \\
1.0295 & (2)\end{array}$ & $\begin{array}{l}3203 \\
2709\end{array}$ & * \\
\hline \pm 5.0 & $\begin{array}{r}.9499 \\
1.0154(3)\end{array}$ & $\begin{array}{l}2034 \\
1779\end{array}$ & * \\
\hline
\end{tabular}

a. Number in brackets denotes the number of iterations to get a converged solution $10^{-5}$ 


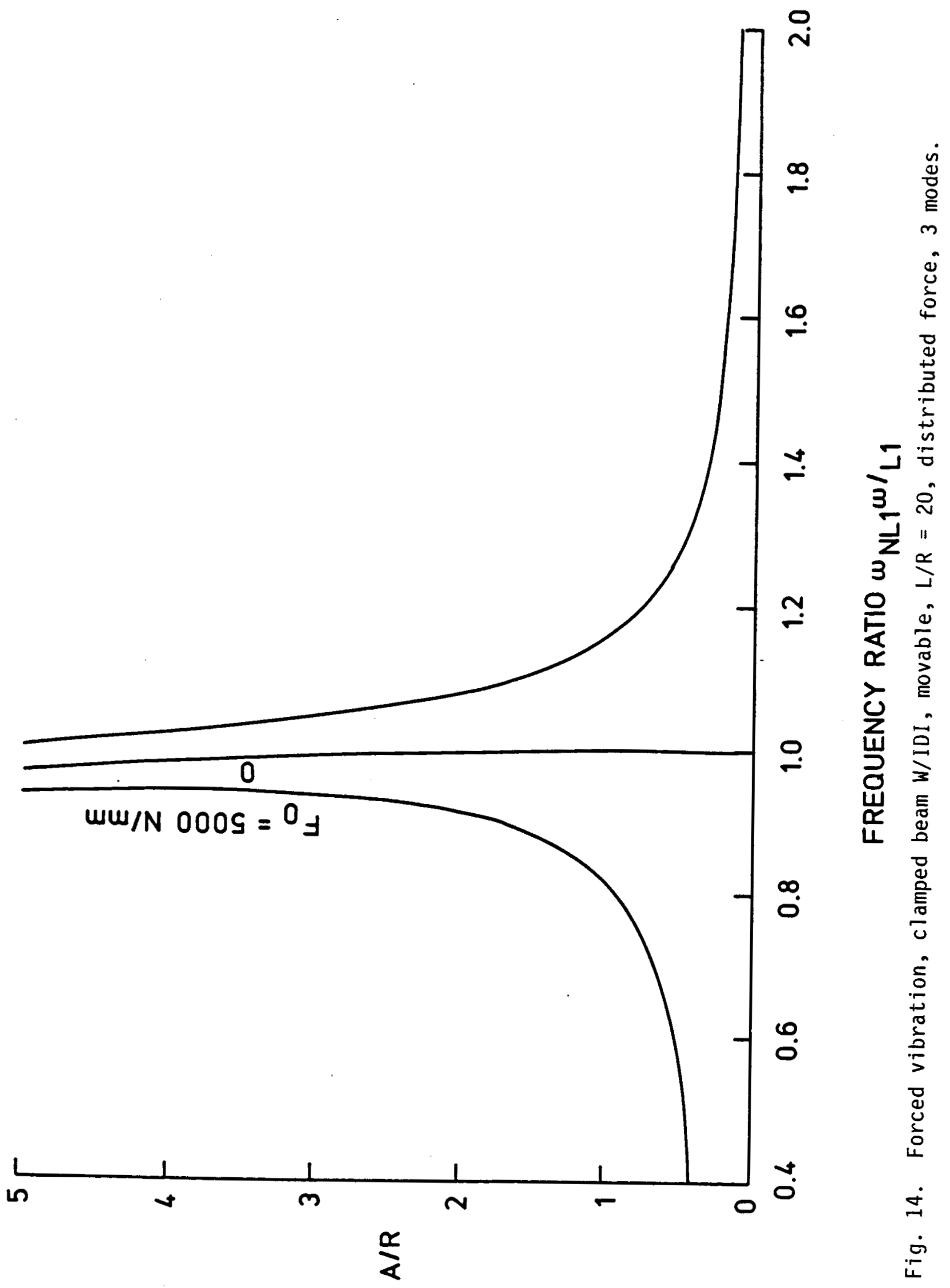




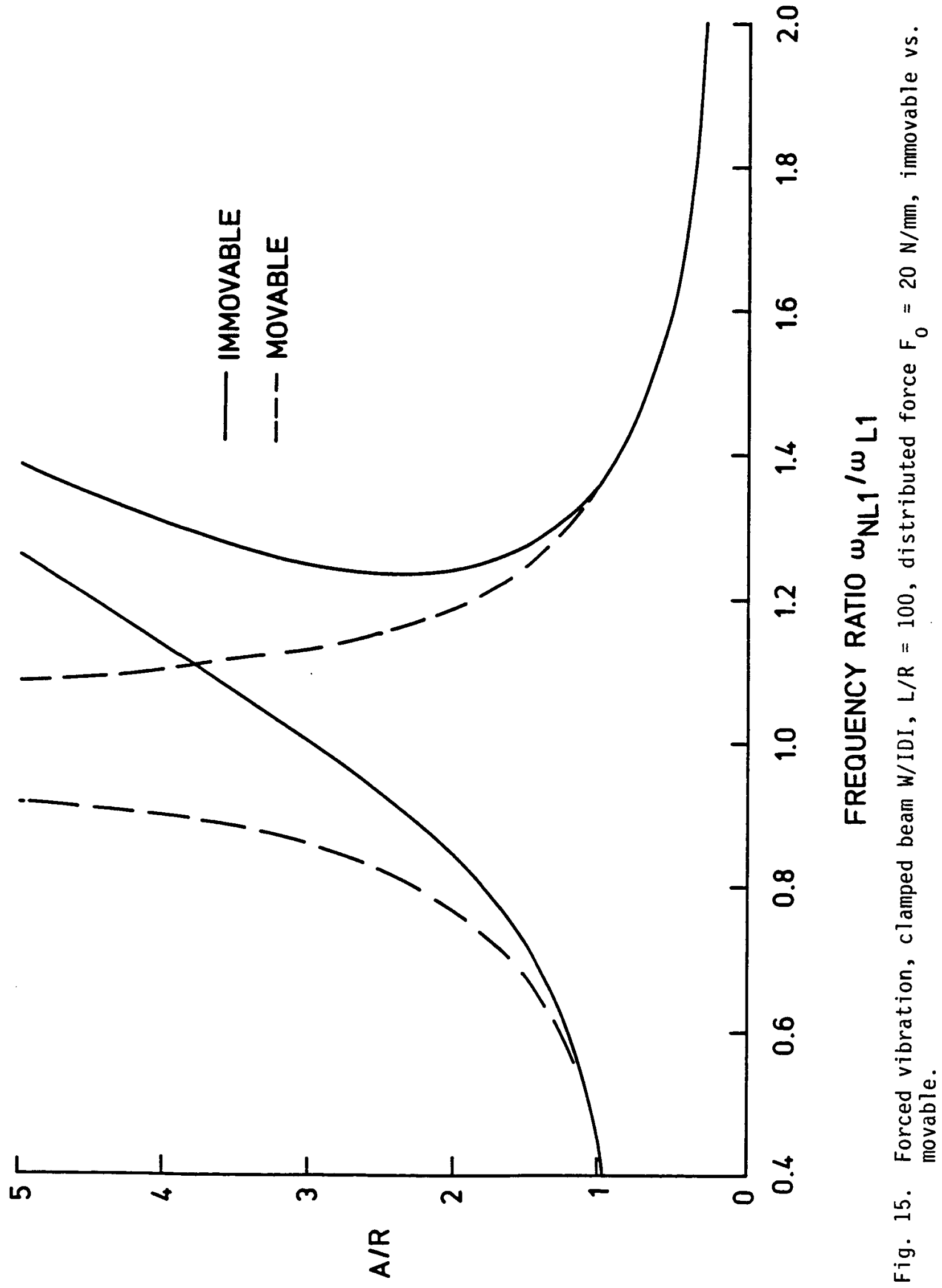


become smaller and smaller. By letting $\ell_{0}$ to be the length of loaded element from coordinate $x=a$ to $x=b$, Eq. (3.55) can be applied to evaluate the constant $c$ which provides the harmonic force matrix [h] in Eq. (3.59). The effect of the length of the loaded element, $\ell_{0}$, is studied and shown in Table 15 for a three-mode clamped immovable beam $(L / R=1010)$ with IDI for the total force $P$ of $0.3 \mathrm{~N}$ at the middle of beam. The simulated distributed force intensity over the loaded element is calculated by $F_{0}=P / \ell_{0}$ for Eq. (3.59). Similarly, the effect of $\ell_{0}$ is shown in Table 16 for a two-mode simply supported immovable beam $(L / R=1010)$ with IDI. The comparison of a beam under the same amount of the total force $P=0.3 \mathrm{~N}$, but different kind of loading, is shown in Figure 16. In this figure, a three-mode clamped immovable beam $(L / R=1010)$ with IDI under a concentrated force at the middle $\left(l_{0} / L=2 \%\right)$ is plotted against a similar beam under uniformly distributed force over the entire beam $\left(F_{0}=0.002 \mathrm{~N} / \mathrm{mm}\right.$. $)$. Similarly, the two-mode simply supported solutions for the total force $P=0.15 \mathrm{~N}, F_{0}=0.001$ $\mathrm{N} / \mathrm{mm}$ for uniform distributed force over entire beam case, are plotted in Figure 17. It shows that the concentrated force cases are much more severe than the uniform distributed force for the cases studied. 
Table 15 Frequency Ratios for Three-Mode Forced Vibration of Clamped Immovable Beam $(L / R=1010)$ with Inplane Displacement and Inertia (IDI) under Concentrated Harmonic Force: Total Force $P=0.3 \mathrm{~N}$

\begin{tabular}{|c|c|c|c|}
\hline \multirow{3}{*}{$A / R$} & \multicolumn{3}{|c|}{ Frequency Ratio, $\omega_{N L 1} / \omega_{L 1}$} \\
\hline & \multicolumn{3}{|c|}{$\left(\ell_{0} / L\right)$ percent } \\
\hline & 5 & 2 & 1 \\
\hline-1.0 & $1.6425(3)^{a}$ & $1.6436 \quad(3)$ & 1.6437 (3) \\
\hline \pm 2.0 & $\begin{array}{r}.5372(4) \\
1.3965 \quad(4)\end{array}$ & $\begin{array}{rr}.5357 & (4) \\
1.3971 & (4)\end{array}$ & $\begin{array}{r}.5354(4) \\
1.3972(4)\end{array}$ \\
\hline \pm 3.0 & $\begin{array}{rr}.8468 & (5) \\
1.3485 & (4)\end{array}$ & $\begin{array}{r}.8462(5) \\
1.3489(4)\end{array}$ & $\begin{array}{r}.8461(5) \\
1.3490 \quad(4)\end{array}$ \\
\hline \pm 4.0 & $\begin{array}{ll}1.0314 & (6) \\
1.3724 & (5)\end{array}$ & $\begin{array}{l}1.0310(6) \\
1.3727 \quad(5)\end{array}$ & $\begin{array}{l}1.0310(6) \\
1.3728(5)\end{array}$ \\
\hline \pm 5.0 & $\begin{array}{ll}1.1879 & (7) \\
1.4356 & (5)\end{array}$ & $\begin{array}{ll}1.1876 & (7) \\
1.4359 & (5)\end{array}$ & $\begin{array}{l}1.1876(7) \\
1.4359(5)\end{array}$ \\
\hline
\end{tabular}

a. Number in brackets denotes the number of iterations to get a converged solution $10^{-5}$ 
Table 16 Frequency Ratios for Two-Mode Nonlinear Forced Vibration of Simply Supported Immovable Beam $(L / R=$ 1010) with Inplane Displacement and Inertia (IDI) under Concentrated Harmonic Force: Total Force $P=0.15 \mathrm{~N}$.

\begin{tabular}{lcccc}
\hline & \multicolumn{5}{c}{ Frequency Ratio, $\omega_{\mathrm{NL1}} / \omega_{\mathrm{L} 1}$} \\
\cline { 2 - 6 } & \multicolumn{5}{c}{$\left(\ell_{0} / \mathrm{L}\right)$ percent } \\
\cline { 2 - 6 } & \multicolumn{5}{c}{2} & \multicolumn{1}{c}{1} \\
\hline-1.0 & $2.1286(2)^{\mathrm{a}}$ & $2.1296(2)$ & $2.1297(2)$ \\
-2.0 & $1.7897(2)$ & $1.7903(2)$ & $1.7904(2)$ \\
\pm 3.0 & $.9949(2)$ & $.9941(2)$ & $.9940(2)$ \\
& $1.8056(2)$ & $1.8060(2)$ & $1.8061(2)$ \\
\pm 4.0 & $1.4658(2)$ & $1.4654(2)$ & $1.4654(2)$ \\
& $1.9625(2)$ & $1.9628(2)$ & $1.9628(2)$ \\
\pm 5.0 & $1.8558(2)$ & $1.8555(2)$ & $1.8555(2)$ \\
& $2.1923(2)$ & $2.1925(2)$ & $2.1925(2)$
\end{tabular}

a. Number in brackets denotes the number of $i$ teratives to get a converged solution $10^{-5}$ 


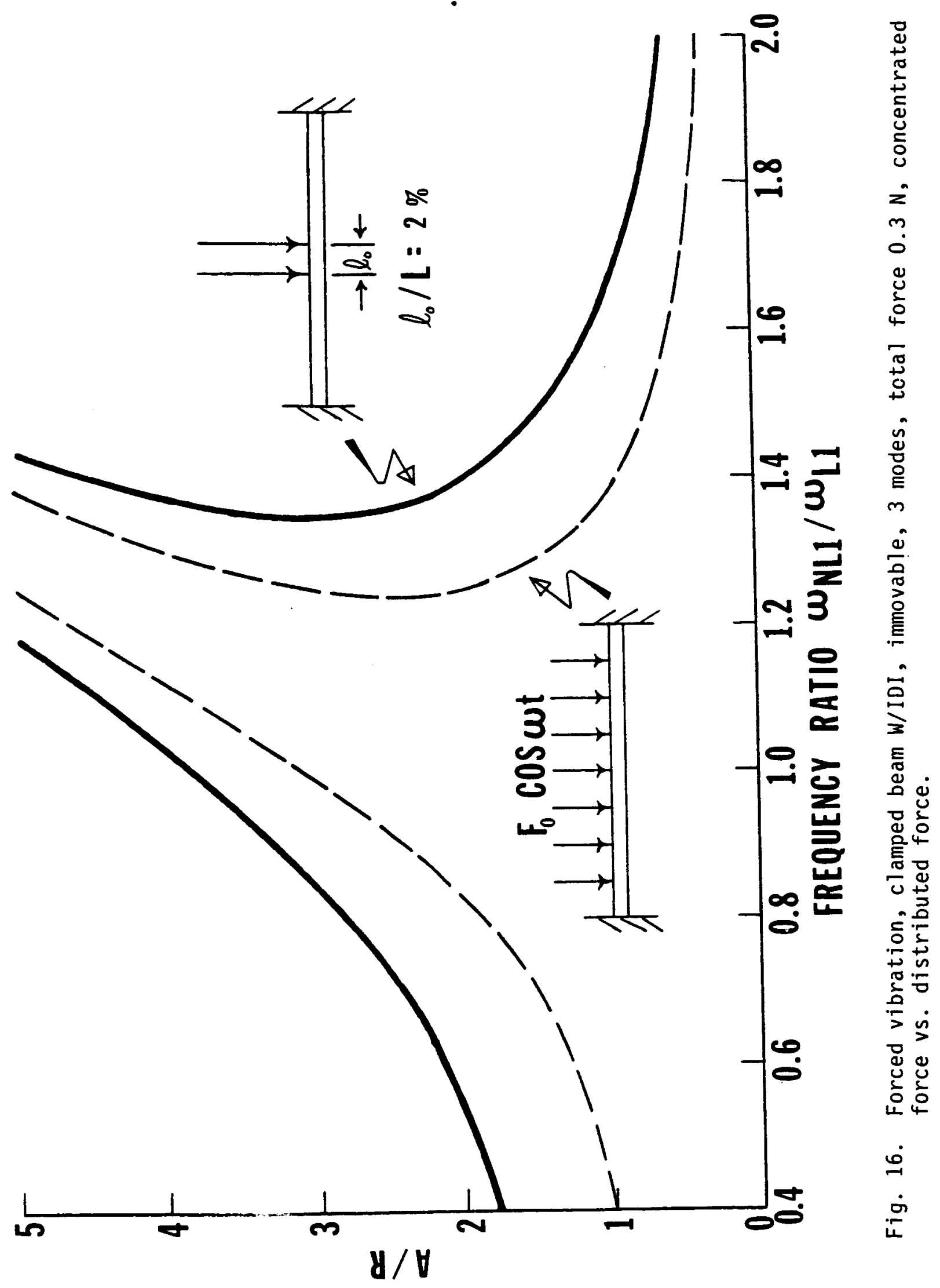




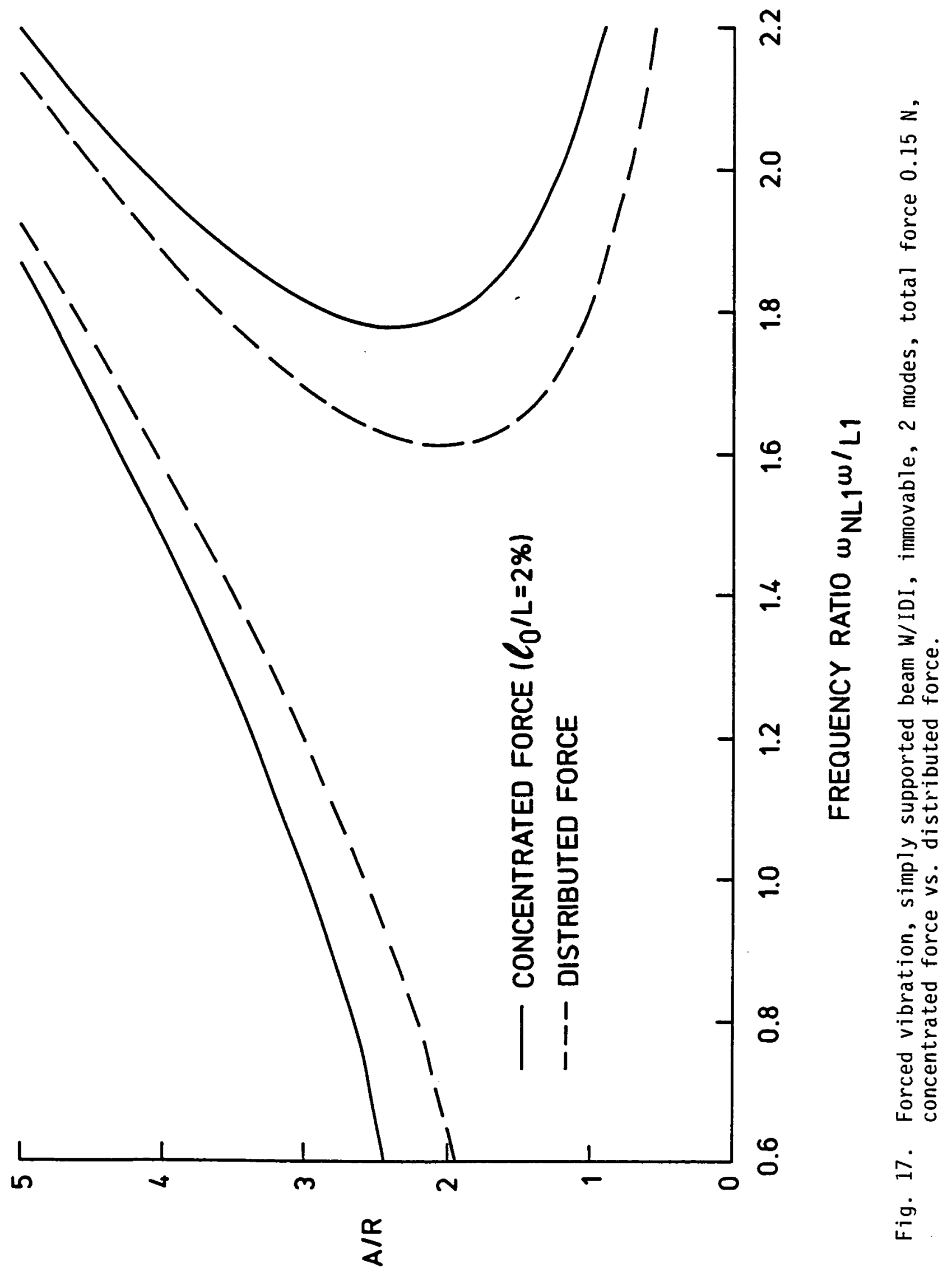


Chapter 6

\section{CONCLUSIONS}

Multiple-mode nonlinear forced vibration of a beam has been analyzed by the finite element method. Inplane (longitudinal) displacement and inertia (IDI) are considered in the formulation. Nonlinear free vibration can be simply treated as a special case of the general forced vibration by setting the harmonic force matrix equal to zero. The effect of the higher modes is more pronounced for the clamped supported beam than the simply supported one. In addition, the beam without inplane displacement and inertia yields more effect in the higher modes than the one with inplane deformation and inertia. The effect of midplane stretching due to large deflection is to increase the nonlinearity. However, the effects of inplane displacement and inertia are to reduce nonlinearity. A beam with end supports restrained from axial movement (immovable case), only the hardening type nonlinearity is observed. For beams of large slenderness ratio $(L / R \geqslant 100)$ with movable end supports, the increase in nonlinearity due to large deflection is partialiy compensated by the reduction in nonlinear due to inplane displacement and inertia. This leads to a negligible hardening type nonlinearity, therefore, the small deflection linear solution can be employed. However, beams of small slenderness ratio $(L / R=20)$ with movable end supports, the softening type nonlinearity is found. The 
concentrated force case yields a more severe response than the uniformiy distributed force case.

The finite element method, in practice, is more suitable to use to analyze modern complex structures. Nonlinear theory can be employed to obtain more accurate solutions and explain new phenomena. By combining the finite element method and nonlinear theory together, the more realistic models of structural responses can be resulted easily and less time consuming. The nonlinear finite element method which is studied herein, may be extended to study many more advanced topic researches, for example, the service life of the structure ( $S-N$ curve), the study in nonlinear random vibration and the effects of sub or super-harmonic excitations. This clearly demonstrates an advantage for researchers to employ this multiple-mode nonlinear vibration in the future. 


\section{REFERENCES}

1. Woinowsky-Krieger, S., "The Effect of an Axial Force on the Vibration of Hinged Bars," Journal of Applied Mechanics, Vol. 17, 1950, pp. 35-37.

2. Eringen, A. C., "On the Non-linear Vibration of Elastic Bars," Quarterly of Applied Mathematics, Vol. 9, 1952, pp. 361-369.

3. Burgreen, B., "Free Vibrations of a Pin-ended Column with Constant Distance Between Pin Ends," Journal of Applied Mechanics, Vol. 18, 1951, pp. 135-139.

4. Woodall, S. R., "On the Large Amplitude Oscillations of a Thin Elastic Beam," International Journal of Non-linear Mechanics, Vol. 1. 1966, pp. 217-238.

5. Raju, I. S., Rao, G. Y. and Raju, K. K., "Effect of Longitudinal or Inplane Deformation and Inertia on the Large Amplitude Flexural Vibrations of Slender Beams and Thin Plates," Journal of Sound and Vibration, Vol. 49, 1976, pp. 415-422.

6. Tseng, W. Y. and Dugundji, J., "Nonlinear Vibrations of a Beam Under Harmonic Excitation," Journal of Applied Mechanics, Vol. , 1970, pp. 292-297.

7. Pandalai, K.A.V., "A General Conclusion Regarding the Large Amplitude Flexural Vibration of Beams and Plates," Israel Journal of Technology, Vol. 11, No. 5, 1973, pp. 321-324.

8. Atluri, S., "Nonlinear Vibrations of a Hinged Beam Including Nonlinear Inertia Effects," Journal of Applied Mechanics, Vol. 40, 1973, pp. 121-126.

9. McDonald, P. H., "Nonlinear Dynamic Coupling in a Beam Vibration," Journal of Applied Mechanics, Vol. 22, 1955, pp. 573-578.

10. Bennett, J. A. and Eisley, J. G., "A Multiple Degree-of-Freedom Approach to Nonlinear Beam Vibrations," AIAA Journal, Vol. 8, 1970, pp. 734-739.

11. Bennett, J. A., "Ultraharmonic Motion of a Viscously Damped Nonlinear Beam," AIAA Journal, Vol. 11, 1973, pp. 710-715.

12. Tseng, W. Y. and Dugundji, J., "Nonlinear Vibrations of a Buckled Beam Under Harmonic Excitation," Journal of Applied Mechanics, Vol. 38, 1971, pp. 467-476. 
13. Srinivasan, A. V., "Non-linear Vibrations of Beams and Plates," International Journal of Non-linear Mechanics, Vol. 1, 1966, pp. 179-191.

14. Nayfeh, A. H., Mook, D. T. and Lobitz, D. W., "A NumericalPerturbation Method for the Non-linear Analysis of Structural Vibrations," AIAA Journa1, Vol. 12, 1974, pp. 1222-1228.

15. Van Dooren, R. and Bouc, R., "Two Mode Sub-harmonic and Harmonic Vibrations of a Non-linear Beam Forced by a Two Mode Harmonic Load," International Journal of Non-linear Mechanics, Vol. 10, 1975, pp. 271-280.

16. Takahashi, K., "Non-linear Free Vibrations of Inextensible Beams," Journal of Sound and Vibration, Vol. 64, 1979, pp. 31-34.

17. Yamaki, N. and Mori, A., "Non-linear Vibrations of a Clamped Beam with Initial Deflection and Initial Axial Displacement, Part I: Theory," Journal of Sound and Vibration, Vol. 71, 1980, pp. 333346 .

18. Yamaki, N., Otomo, K. and Mori, A. "Non-linear Vibrations of a Clamped Beam with Initial Deflection and Initial Axial Displacement, Part II: Experiment," Journal of Sound and Vibration, Vol. $71,1980, \mathrm{pp} .347-360$.

19. Mei, C., "Non-linear Vibrations of Beams by Matrix Displacement Method," AIAA Journa 1, Vol. 10, 1972, pp. 355-357.

20. Rao, G. V., Raju, K. K. and Raju, I. S., "Finite Element Formulation for Large Amplitude Free Vibrations of Beams and Orthotropic Circular Plates," Computers and Structures, Vol. 6, 1976, pp. 169-172.

21. Reddy, J. N. and Singh, I. R., "Large Deflections and LargeAmplitude Free Vibrations of Straight and Curved Beams," International Journal for Numerical Methods in Engineering, Vol. 17, 1981, pp. 829-852.

22. Mei, C. and Decha-Umphai, K., "A Finite Element Method for Nonlinear Forced Vibrations of Beams," Journal of Sound and Vibrations, Vol. 102, 1985, pp. 369-380.

23. Mei, C. and Decha-Umphai, K., "A Finite Element Method for Nonlinear Forced Vibrations of Rectangular Plates," AIAA Journal, Vol. 23, 1985, pp. 1104-1110.

24. Decha-Umphai, K. and Mei, C., "Finite Element Method for Non-linear Forced Vibrations of Circular Plates," International Journal for Numerical Methods in Engineering, Vol. 23, 1986, pp. 1715-1726. 
25. Zienkiewicz, 0. C., "The Finite Element Method in Engineering Science," McGraw Hill Book Co., 1971, pp. 421.

26. Busby, H. R. and Weingarten, V. I., "Non-linear Response of a Beam to Periodic Loading," International Journal of Non-linear Mechanics, Vol. 7, 1972, pp. 289-303.

27. Cheung, Y. K. and Lau, S. L., "Incremental Time-Space Finite Strip Method for Non-linear Structural Vibrations," Earthquake Engineering and Structural Dynamics, Vol. 10, 1982, pp. 239-253.

28. Sathyamoorthy, M., "Nonlinear Analysis of Beams, Part I: A Survey of Recent Advances," The Shock and Vibration Digest, Vol. 14, No. 8, 1982, pp. 7-18.

29. Sathyamoorthy, M., "Nonlinear Analysis of Beams, Part II: Finite Element Methods," The Shock and Vibration Digest, Vol. 14, No. 8, 1982, pp. 19-35.

30. Hsu, C. S., "On the Application of Elliptic Functions in Non-linear Forced Oscillations," Quarterly Applied Mathematics, Vol. 17, 1966, pp. 393-407.

31. Guyan, R. J., "Reduction of Stiffness and Mass Matrices," AIAA Journal, Vol. 3, No. 2, 1965, pp. 380.

32. Abramowitz, M. and Stegun, I. A., Handbook of Mathematica 1 Functions, Dover Publications, Inc., 1970, pp. 886.

33. Bergan, P.G. and Clough, R.W., "Convergence Criteria for Iterative Process," AIAA Journa 1, Vo1. 10, 1972, pp. 1107-1108. 


\section{APPEMDIX}

\section{CONVERGENCE CRITERIA}

Three displacement convergence criteria (norms) used by Bergan and Clough $^{33}$ for multiple-mode nonlinear free and forced vibrations by finite element method are employed. These three norms are the maximum norm, the modified absolute norm and the modified Euclidean norm.

The maximum norm is defined as

$$
\|\varepsilon\|_{M}=\max _{j}\left|\frac{\Delta v_{j}}{v_{j, r e f}}\right|
$$

The modified absolute norm is defined as

$$
\|\varepsilon\|_{A}=\frac{1}{N} \sum_{j=1}^{N}\left|\frac{\Delta v_{j}}{v_{j, r e f}}\right|
$$

The modified Euclidean norm is defined as

$$
\|\varepsilon\|_{E}=\left(\frac{1}{N} \sum_{j=1}^{N}\left|\frac{\Delta v_{j}}{v_{j, r e f}}\right|^{2}\right)^{1 / 2}
$$

In these expressions, $\Delta v_{j}$ is the change in displacement component $j$ during iterative cycle $n$, and $v_{j}$, ref is the reference displacement which is the largest displacement component of the corresponding "type". For instance in a nonlinear vibration problem involving deflections $w$ and rotations $w, x$, the reference displacement are the largest deflection and the largest rotation of the corresponding type. 